\title{
Mutant GTF2I induces cell transformation and metabolic alterations in thymic epithelial cells
}

\author{
In-Kyu Kim $\mathbb{1}^{1} \cdot$ Guanhua Rao $^{1} \cdot$ Xiaoliang Zhao $^{1} \cdot$ Ruzong Fan ${ }^{1} \cdot$ Maria Laura Avantaggiati ${ }^{1} \cdot$ Yisong Wang $^{1,2} \cdot$ \\ Yu-Wen Zhang ${ }^{1} \cdot$ Giuseppe Giaccone $^{1}$
}

Received: 28 June 2019 / Revised: 15 January 2020 / Accepted: 16 January 2020 / Published online: 7 February 2020

(c) The Author(s), under exclusive licence to ADMC Associazione Differenziamento e Morte Cellulare 2020

\begin{abstract}
The pathogenesis of thymic epithelial tumors (TETs) is poorly understood. Recently we reported the frequent occurrence of a missense mutation in the GTF2I gene in TETs and hypothesized that GTF2I mutation might contribute to thymic tumorigenesis. Expression of mutant TFII-I altered the transcriptome of normal thymic epithelial cells and upregulated several oncogenic genes. Gtf2i L424H knockin cells exhibited cell transformation, aneuploidy, and increase tumor growth and survival under glucose deprivation or DNA damage. Gtf $2 i$ mutation also increased the expression of several glycolytic enzymes, cyclooxygenase-2, and caused modifications of lipid metabolism. Elevated cyclooxygenase-2 expression by $G t f 2 i$ mutation was required for survival under metabolic stress and cellular transformation of thymic epithelial cells. Our findings identify GTF2I mutation as a new oncogenic driver that is responsible for transformation of thymic epithelial cells.
\end{abstract}

\section{Introduction}

Thymic epithelial tumors (TETs) are uncommon, primary neoplasms of the anterior mediastinum derived from the thymic epithelium, with an annual incidence ranging from 1.3 to 3.2/million [1, 2]. The World Health Organization histologic classification distinguishes thymomas $(\mathrm{A}, \mathrm{AB}, \mathrm{B} 1, \mathrm{~B} 2$, and $\mathrm{B} 3$ ), from thymic carcinomas (TC) [3]. However, the complex and frequently mixed histomorphology renders TETs one of the most challenging tumors to classify histologically [4]. Prognosis worsens progressively from type A to

Edited by R. Johnstone

Supplementary information The online version of this article (https:// doi.org/10.1038/s41418-020-0502-7) contains supplementary material, which is available to authorized users.

In-Kyu Kim

ingyu.kim80@gmail.com

Giuseppe Giaccone

gg496@georgetown.edu

1 Department of Oncology, Lombardi Comprehensive Cancer Center, Georgetown University, Washington, DC 20057, USA

2 Basic and Mechanistic Research Branch, Division of Extramural Research, National Center for Complementary and Integrative Health (NCCAIH), NIH, Bethesda, MD 20892, USA
TC: 10 -year survival is $90-95 \%$ in types A through B1, and 5 -year survival rates for $\mathrm{B} 2, \mathrm{~B} 3$, and $\mathrm{TC}$ are $75 \%, 70 \%$, and $48 \%$, respectively [5]. The etiology of TETs is obscure, aside from the controversial reports of an association with $\mathrm{EB}$ virus infection [6], and thymomas can be commonly associated with autoimmune diseases such as myasthenia gravis. In addition, the genetic/molecular aberrations associated with TETs are largely unknown and a lack of appropriate preclinical models hinders investigation of the cause of TETs.

Using exome and RNA sequencing, we recently reported a highly recurrent unique somatic mutation of GTF2I in the least aggressive thymomas, and predicted that GTF2I mutation is necessary for the founder tumor clone in thymus [7]. These findings were later confirmed by the The Cancer Genome Atlas (TCGA) program [8]. GTF2I encodes TFII-I, a transcription factor, and there are currently at least five known splice variants of GTF2I recognized in the human genome. We discovered that the $\beta$ and $\delta$ isoforms of TFII-I are predominantly expressed in TETs; these isoforms are known as negative or positive regulators in gene transcription with distinct subcellular localization in response to mitogen signal [9]. The observed GTF2I T1211A (L424H) missense mutation at chr.7:74146970 leads to p.Leu404His and p.Leu383His substitution in the $\beta$ and $\delta$ isoforms of TFII-I, respectively.

The human TFII-I protein belongs to a family of transcription factors, consisting of three related genes (GTF2I 
and its pseudogenes GTF2IP1, and LOC100093631) that are located in close proximity on the long arm of chromosome 7. A portion of the long arm of chromosome 7 is deleted in a haplo-insufficient manner in Williams-Beuren syndrome, a genetic disorder characterized by marked defects in neurological and cardiovascular development [10]. Originally TFII-I was identified as a novel type of transcription initiation factor that binds to multiple promoter elements including a pyrimidine-rich initiator (Inr). TFII-I is a multifunctional protein associated with the transcriptional regulation of several genes that control cell proliferation, cell cycle, angiogenesis, cellular stress response, and development, through sequence-specific DNA binding [11]. Despite the many functions of TFIII, alterations of GTF2I in tumors have not been reported until recently.

Here, we investigated the effects of GTF2I mutation on transcriptional regulation, and several biological and metabolic processes involved in tumorigenesis. We demonstrated that the mutant TFII-I (mtTFII-I) expression in thymic epithelial cells (TECs) results in upregulation of oncogenes and cell transformation. Gtf $2 i$ mutation conferred cell transformation and survival advantage through COX-2 expression in response to metabolic stress and promoted tumor growth in vivo.

\section{Materials and methods}

\section{Cell culture}

All mouse normal TEC lines (TEC71, TEC100.4, TEC41.2, TEC301, and Z210r; a kind gift from Dr. Julien Sage, Stanford University) were maintained in RPMI-1640 (Thermo Fisher; Waltham, MA, USA), and 293T cells were grown in DMEM supplemented with 10\% FBS (Thermo Fisher). NIH-3T3 cells were maintained in DMEM supplemented with $10 \%$ bovine calf serum (Thermo Fisher). All cell lines were cultivated as monolayer in each optimal medium with $2 \%$ penicillin-streptomycin (Thermo Fisher). Doxycycline Hydrochloride was purchased from Thermo Fisher and solubilized in distilled water. For metabolic studies, RPMI-1640 with no glucose, dialyzed FBS, and Dglucose from Thermo Fisher were used. Cisplatin and Doxorubicin were purchased from Selleckchem (Houston, TX, USA).

\section{Production of lentiviral particles}

293T cells were plated in $10 \mathrm{~cm}$ culture dishes and were transfected with $6 \mu \mathrm{g}$ lentiviral vector, $0.6 \mu \mathrm{g}$ lenti-Rev/PM2/-Tat, and 1.2 $\mu$ g lenti-Vsv-G at the ratio 10:1:1:1:2 using X-tremeGENE 9 (SIGMA; St. Louis, MO, USA), the next day. Growth medium was changed after $24 \mathrm{~h}$ and virus-containing medium was collected between 36 and 48 $\mathrm{h}$ after transfection and filtered through $0.45 \mu \mathrm{m}$ lowbinding PES membrane. Virus particles were stored at -80 ${ }^{\circ} \mathrm{C}$ until use.

\section{Doxycycline inducible system}

Mutated GTF2I [7] was amplified by PCR using the following primers: 5'-CACCATGGCCCAAGTTGCAATGT C-3', and 5'-AAACCACGTGGGGTCTGGTTCTTG-3'. PCR fragments were clone into the pENTR/D-TOPO (Thermo Fisher), and subsequently moved into a pLIX402 lentiviral vector (Addgene; Cambridge, MA, USA) using Gateway LR Clonase II Enzyme mix (Thermo Fisher) according to the manufacturer's instructions. The insert sequence in the plasmid was sequenced, and confirmed HAtag expression under the control of doxycycline in 293T cells first. Mouse thymic epithelial cells (mTECs) were seeded $\left(3-4 \times 10^{4}\right)$ in six-well plates and infected with lentivirus the next day. After $48 \mathrm{~h}$ infection, $3-5 \mu \mathrm{g} / \mathrm{mL}$ puromycin was used for selection and puromycin-resistant single clones were picked by pyrex cloning cylinder (SIGMA). Five micrograms of the pLIX402 plasmids with mutated GTF2I isoforms were transfected into TEC100.4 cells using the Nucleofector Kit V (Lonza; Salisbury, MD, USA) with Nucleofector $2 \mathrm{~b}$ device under T-30 program. After $48 \mathrm{~h}$ transfection, $3 \mu \mathrm{g} / \mathrm{mL}$ puromycin was used for selection and puromycin-resistant single clones were picked by Pyrex cloning cylinder.

\section{Establishment of stable knockdown (KD) cells}

pLKO.1 from Addgene (\#8453), two COX-2 shRNA (TRCN0000067941 and TRCN0000067939), PFKFB2 shRNA (TRCN0000361450 and TRCN0000361451), PFKP (TRCN0000025962 and TRCN0000025916), and ENO2 shRNA (TRCN0000340138 and TRCN0000340139) were purchased from Sigma. Cells were infected with shRNA lentiviral particles and selected by $10 \mu \mathrm{g} / \mathrm{ml}$ of puromycin. Cells transfected with pLKO.1 were used as a control.

\section{Western blot analysis and antibodies}

Cells were harvested and lysed in $1 \times$ lysis buffer [ $60 \mathrm{mM}$ Tris (pH 7.4), $25 \mathrm{mM}$ HEPES, $150 \mathrm{mM} \mathrm{NaCl}, 10 \%$ glycerol, $5 \mathrm{mM}$ EDTA, 1\% Triton X-100, $5 \mathrm{mM} \mathrm{Na3VO4,} 50$ $\mathrm{mM} \mathrm{NaF}$, two pills protease inhibitor cocktail tablets] on ice for $45 \mathrm{~min}$ and centrifuged at $15,000 \mathrm{rpm}$ for $15 \mathrm{~min}$. Cell lysates were separated by 4-20\% SDS-PAGE and transferred to a PVDF membrane. Subsequently, the membrane was incubated in TBST supplemented with 5\% nonfat dry milk or BSA and probed with the appropriate primary antibodies. The bound antibodies were visualized with a 
suitable secondary antibody conjugated with horseradish peroxidase using enhanced chemiluminescence reagent WESTSAVE up by PXi6 imaging system. The following primary antibodies were used: Aldolase A (8060, Cell Signaling), Bcl2 (sc-7382, Santa Cruz), Bcl-xL (sc-8392, Santa Cruz), cleaved Caspase-3 (9661, Cell Signaling), COX-1 (4841, Cell Signaling), COX-2 (12282, Cell Signaling), Enolase-1 (3810, Cell Signaling), Enolase-2 (8171, Cell Signaling), p-Erk1/2 (9101, Cell Signaling), Erk1/2 (9102, Cell Signaling), FGFBP (sc-68177, Santa Cruz), cfos (sc-52, Santa Cruz), GAPDH (5174, Cell Signaling), HA (H9658, SIGMA), Hexokinase I (2024, Cell Signaling), Hexokinase II (2867, Cell Signaling), $\gamma \mathrm{H} 2 \mathrm{AX}$ (613402, BioLegend), c-kit (sc-168 and sc-365504, Santa Cruz), Lactate Dehydrogenase (ab52488, Abcam), Mdm2 (sc-965, Santa Cruz), c-myc (ab51154, Abcam), PARP (9542, Cell Signaling), cleaved PARP (9544, Cell Signaling), PDCD4 (9535, Cell Signaling), PDHK1 (3820, Cell Signaling), PFKP (8164, Cell Signaling), PFKFB2 (13045, Cell Signaling), PFKFB3 (13123, Cell Signaling), PGAM1 (12098, Cell Signaling), PKM2 (4053, Cell Signaling), PKM1/2 (3190, Cell Signaling), p16 (ab189034, Abcam), p21 (556431, BD Bioscience), p53 (2524, Cell Signaling), phospho-p53 (9284, Cell Signaling), Slug (9585, Cell Signaling), Snail (sc-271977, Santa Cruz), TFII-I (4562, Cell Signaling), TWIST (GTX127310, GeneTex), $\alpha$-Tubulin (T6199, SIGMA), VEGFC (ab9546, Abcam), VEGFD (sc373866, Santa Cruz), VEGFR1 (ab32152, Abcam), VEGFR2 (sc-504, Santa Cruz), and WNT2B (sc-98737, Santa Cruz).

\section{Immunostaining}

Cells were seeded on glass coverslips in 12-well plates. In the doxycycline inducible system, cells were incubated with/without $2 \mu \mathrm{g} / \mathrm{ml}$ doxycycline for $24 \mathrm{~h}$. After cells were fixed with $4 \%$ paraformaldehyde and permeabilized with $0.1 \%$ Triton X-100, cells were incubated with $1 \%$ BSA (in PBS). Then, cells were incubated with primary antibody: HA (1:200 \#H9658, SIGMA), Vimentin (1:200 \#5741, Cell Signaling), V5 (R960-25, Thermo Fisher), or Texas Red-X phalloidin (1:50 \#T7471, Thermo Fisher) in 1\% BSA for overnight at $4{ }^{\circ} \mathrm{C}$. Following PBS washing, cells were incubated with Alexa Fluor 488 (\#A-11029, Thermo Fisher) or Alexa Fluor 555 conjugate (\#A-21422, Thermo Fisher) secondary antibody for $1 \mathrm{~h}$ at room temperature. Labeled cells were rinsed with PBS and mounted in VECTASHIELD Hardset Mounting Medium (\#H-1500, Vector Laboratories; Burlingame, CA, USA) or ProLong Gold Antifade Reagent with DAPI (\#8961, Cell Signaling). The cells were examined by immunofluorescent microscope (Olympus).

\section{Quantitative RT-PCR (qRT-PCR)}

Total RNA was isolated using the RNeasy Plus Mini Kit (\#74134, QIAGEN; Germantown, MD, USA) according to the manufacturer's instructions. qRT-PCR was carried out using ABI 7900HT Fast Real-time PCR system (Applied Biosystems) and the QuantiTect SYBR Green RT-PCR Kit (\#204243, QIAGEN). Reactions were run in three independent experiments $(n=3)$. The used primers are described in Supplementary Table S1.

\section{Gene expression microarray analysis}

Total RNA was prepared using the RNeasy Plus Mini Kit (QIAGEN) according to manufacturer's protocol. The TEC100.4 + pLIX402/TFII-I- $\beta$ mt and - $\delta$ mt inducible cells were treated with/without doxycycline, and total RNA was prepared $24 \mathrm{~h}$ later. Microarrays were performed at the Genomics and Epigenomics Shared Resources at Georgetown University: total RNAs were subjected to hybridization on the Agilent SurePrint G3 mouse gene expression V2 $8 \times 60 \mathrm{~K}$ microarray kit (Agilent; Savage, MD, USA) according to the manufacturer's protocol. Briefly, $200 \mathrm{ng}$ of total RNA was used to generate fluorescent cRNA using the Agilent Low Input Quick Amp labeling Kit, One-Color. The cRNA was hybridized to the array and scanned using the Agilent G2505C DNA Scanner System, and the data were extracted using Agilent Feature Extraction Software v11.5.11. The web-based functional annotation tool DAVID was used for functional gene enrichment analysis of differentially expressed genes ( $>1.5$-fold).

\section{Cell proliferation assay}

Cells were placed in 6 or $10 \mathrm{~cm}$ culture dishes and viable cells were counted with a hemocytometer or TC20 automated cell counter (Bio-rad; Hercules, CA, USA) using trypan blue staining at indicated time points. The Cell Counting Kit-8 (VitaScientific; College Park, MD, USA) was also used to further determine cell proliferation following the manufacturer's manual. One thousand cells were plated in 96-well plates and incubated for indicated time point. CCK8 solution was added and followed by incubation for $1 \mathrm{~h}$ at $37^{\circ} \mathrm{C}$. The absorbance at $450 \mathrm{~nm}$ was measured by Glomax.

\section{Cell cycle analysis}

Cells were plated in $10 \mathrm{~cm}$ dishes and incubated overnight. Next day, growth medium was changed with fresh medium containing normal or $5 \mathrm{mM}$ glucose and incubated for $72 \mathrm{~h}$. Following incubation, cells were fixed with ethanol and washed with cold PBS. After centrifugation, cell pellets 
were mixed with Propidium iodide (PI) solution and incubated for $30 \mathrm{~min}$ at room temperature in dark environment. Cell cycle was analyzed using FACSCalibur Flow Cytometer (BD Bioscience). Acquired data were processed using the FlowJo software (Tree Star). For aneuploidy analysis, DNA content was defined as DNA Index (DI) and mouse spleen cells were used as internal control. DNA aneuploidy was characterized by the DI (diploid: DI $=1$, aneuploid: $\mathrm{DI} \neq 1$ ) and obtained by dividing additional G1 peak by the residual G1 peak in the sample.

\section{Annexin V/PI staining}

Cells were washed with PBS and harvested by trypsinization, resuspended in binding buffer, and then incubated with Annexin V-FITC antibody for $20 \mathrm{~min}$ in dark environment. PI was added before proceeding to flow cytometry analysis.

\section{TUNEL assay}

In Situ Cell Death Detection Kit (SIGMA) was used to assess cell apoptosis following the manufacturer's instructions. Cells were plated in six-well plates with cover slip and incubated overnight. Next day, growth medium was replaced with normal or $5 \mathrm{mM}$ glucose medium and cells were incubated for 48-72 h. After fixation (4\% paraformaldehyde) and permeabilization, cells were stained using the TUNEL reaction mixture in dark environment. Labeled cells were mounted in VECTASHIELD Hardset Mounting Medium and examined by immunofluorescence microscope. TUNEL-positive cells were counted to quantify the apoptosis rate.

\section{CRISPR/Cas9n-mediated engineering of the normal mTECs genome}

Cells $\left(1 \times 10^{6}\right)$ were co-transfected with $1.5 \mu \mathrm{g}$ of each two gRNAs (pU6-gRNA, SIGMA), $4 \mu \mathrm{g}$ of pSpCas9n (D10A nickase mutant, PX462, Addgene), and $25 \mu \mathrm{g}$ of donor DNA (3080 bp). Transfection was performed using the Amaxa nucleofector kit $\mathrm{V}$ with $\mathrm{T}-30$ program at six-well culture plate. The oligonucleotides used for gRNA were: 5'ACGTCGACGGCCTTCTAAA， 5'-GAGAGGATATTG CTGGCGA- ${ }^{\prime}$. Because of the low efficiency with knockin (KI) based on homology-directed repair strategy with CRISPR system, we could not get correct clone while we screened hundreds clones with single-stranded oligodeoxynucleotides used as the homologous recombination (HR) donor template. Then we adopted a new strategy to use Scr7, a DNA ligase IV inhibitor [12], with double-strand DNA which has a new restriction enzyme site $(S p h I)$ as a HR template. After $6 \mathrm{~h}$ incubation, the culture medium was changed with fresh medium containing $1 \mu \mathrm{M}$ SCR7, and then incubated for $72 \mathrm{~h}$. Puromycin $(8 \mu \mathrm{g} / \mathrm{ml})$ was used for selection and single colonies were picked and transferred to 96- or 48-well plates to expand. Genomic DNAs of all clones were isolated by using the GenElute ${ }^{\mathrm{TM}}$ mammalian genomic DNA miniprep kit (SIGMA) and target region was amplified by PCR. CRISPR/Cas9n-mediated HR was confirmed by two-step PCR and restriction enzyme digestion with SphI. Two primers set (5'-CATGCTTGTTCTCAGTGC TTTC-3' ${ }^{\prime} 5^{\prime}$-CCCTCGTAAGGGCTATGTAAG- $3^{\prime}$ for 1 st PCR; 5'-TGTGGTTCACTTCTGTAGACAAAGC-3', 5'-TG TAGTGATACCGGCTAGACC-3' for 2nd PCR) were used for amplification. The cycling conditions used were as follows: $95^{\circ} \mathrm{C}$ for $2 \mathrm{~min} ; 30$ cycle $\left(95^{\circ} \mathrm{C}\right.$ for $20 \mathrm{~s}, 61^{\circ} \mathrm{C}$ for $20 \mathrm{~s}$, $72{ }^{\circ} \mathrm{C}$ for $35 \mathrm{~s}$ to $2.5 \mathrm{~min}$ ); $72{ }^{\circ} \mathrm{C}$ for $3 \mathrm{~min}$; hold at $4{ }^{\circ} \mathrm{C}$. PCR products were purified using the GeneJET PCR purification kit (Thermo Fisher), and then digested purified PCR DNA with SphI to assess KI. Different cleavage patterns were detected under $2 \%$ agarose gel electrophoresis. After selection with SphI, potential candidates were sequenced and the insertion of specific mutation on Gtf2i gene confirmed. To check Indel (insertion/deletion) rate, $1-2 \times 10^{6}$ cells were transfected with peSpCas9-mGTF2I using Nucleofector and applied puromycin next day. After $48 \mathrm{~h}$, cells were washed with PBS and fresh medium was added. About 2 weeks later, genomic DNA was isolated from expanded cells and CRISPR/Cas9 target region was amplified with GTF2I-KI-F and $-\mathrm{R}$ primers. Five microliters of the amplified DNA was eletrophoresed on $1 \%$ agarose gel to confirm single band was produced. Subsequently, PCR products were purified and eluted with $30 \mu \mathrm{l}$ of the elution buffer and DNA was mixed with $5 \mu \mathrm{l}$ of $10 \times \mathrm{NEB}$ buffer 2 and water to a final volume of $50 \mu \mathrm{l}$. PCR products were rehybridized with following conditions: $95^{\circ} \mathrm{C}$ for $10 \mathrm{~min}$; ramp down to $85^{\circ} \mathrm{C}$ at $-2{ }^{\circ} \mathrm{C} / \mathrm{s} ; 85^{\circ}$ $\mathrm{C}$ for $1 \mathrm{~min}$; ramp down to $75^{\circ} \mathrm{C}$ at $-0.3{ }^{\circ} \mathrm{C} / \mathrm{s} ; 75^{\circ} \mathrm{C}$ for 1 min; ramp down to $65^{\circ} \mathrm{C}$ at $-0.3^{\circ} \mathrm{C} / \mathrm{s} ; 65^{\circ} \mathrm{C}$ for $1 \mathrm{~min}$; ramp down to $55^{\circ} \mathrm{C}$ at $-0.3{ }^{\circ} \mathrm{C} / \mathrm{s} ; 55^{\circ} \mathrm{C}$ for $1 \mathrm{~min}$; ramp down to $45^{\circ} \mathrm{C}$ at $-0.3{ }^{\circ} \mathrm{C} / \mathrm{s} ; 45^{\circ} \mathrm{C}$ for $1 \mathrm{~min}$; ramp down to $35^{\circ} \mathrm{C}$ at $-0.3{ }^{\circ} \mathrm{C} / \mathrm{s} ; 35^{\circ} \mathrm{C}$ for $1 \mathrm{~min}$; ramp down to $25^{\circ} \mathrm{C}$ at $-0.3{ }^{\circ} \mathrm{C} / \mathrm{s}$; $25^{\circ} \mathrm{C}$ for $1 \mathrm{~min}$; hold at $4 \mathrm{C}$. Reannealed DNA was mixed with $1 \mu \mathrm{l}(10 \mathrm{U}) \mathrm{T} 7$ endonuclease I (NEB) and incubated at $37^{\circ} \mathrm{C}$ for $45 \mathrm{~min}$. Digested products were visualized on a $2 \%$ agarose gel and Indel occurrence was estimated with the following formula: Indel $(\%)=100 \times\left[1-\left(1 \text {-fraction }_{\text {cut }}\right)^{1 / 2}\right][13]$.

\section{In vivo mouse experiment}

Control or KI cells $\left(8 \times 10^{6}\right.$ cells in $20 \%$ matrigel) were injected subcutaneously into the right flanks of six-week old athymic nude female mice (Charles River Laboratories; Wilmington, MA, USA). Tumors were measured with caliper to estimate volume $\left(0.5 \times\right.$ width $^{2} \times$ length $)$ twice a week and all animal experiments were conducted under a protocol approved by the Georgetown University Animal Care Committee. 


\section{Metabolic analysis}

Cells were grown in normal culture condition or lowglucose condition $(5 \mathrm{mM}$ glucose was added in no glucose RPMI-1640 medium) in $15 \mathrm{~cm}$ culture dishes. Cells were harvested with cell scraper, and samples were prepared in quintuplicate. For metabolite extraction, the cells were resuspended in $150 \mu \mathrm{l}$ of chilled $35 \%$ water, $25 \% \mathrm{MeOH}$, and $40 \%$ isopropanol containing internal standards $(50 \mu \mathrm{l}$ of $1 \mathrm{mg} / \mathrm{ml}$ 4-nitrobenzoic acid and $10 \mu \mathrm{l}$ of $1 \mathrm{mg} / \mathrm{ml}$ debrisoquine added to $10 \mathrm{ml}$ of $35 \%$ water, $25 \% \mathrm{MeOH}$, and $40 \%$ isopropanol). The cells were given heat shock treatment by plunging the tubes into dry ice for $30 \mathrm{~s}$ and immediately into $37^{\circ} \mathrm{C}$ water bath for $90 \mathrm{~s}$, followed by sonication for $30 \mathrm{~s}$. The freeze thaw cycle was repeated. The samples were vortexed and incubated on ice for $20 \mathrm{~min}$ followed by addition of $150 \mu \mathrm{l}$ of acetonitrile. The samples were then transferred to $-20^{\circ} \mathrm{C}$ for overnight incubation and subsequently centrifuged at $4{ }^{\circ} \mathrm{C}$ for $20 \mathrm{~min}$ at $13,000 \mathrm{rpm}$. The supernatant was transferred to a MS vial for UPLC TOF MS analysis and the pellets processed for protein quantification. Each sample $(2 \mu \mathrm{l})$ was injected onto three different columns: a reverse-phase $2.1 \times 50 \mathrm{~mm}$ Acquity $1.7 \mu \mathrm{m} \mathrm{BEH}$ C18 column (isolate most metabolites) (Waters Corp; Milford, MA, USA), a $2.1 \times 100 \mathrm{~mm}$ Acquity $1.7 \mu \mathrm{m}$ CSH C18 column (Waters Corp) and a $2.1 \times 100 \mathrm{~mm}$ Acquity $1.8 \mu \mathrm{m}$ HSS T3 column (specific with polar metabolites) (Waters Corp) using an Acquity UPLC system (Waters Corp). The gradient mobile phase for BEH $\mathrm{C} 18$ column consisted of solvent A (100\% water with $0.1 \%$ formic acid), solvent B (100\% acetonitrile with $0.1 \%$ formic acid), and solvent D (90\% isopropanol and $10 \%$ acetonitrile with $0.1 \%$ formic acid). The column temperature was set at $40{ }^{\circ} \mathrm{C}$ and flow rate of $0.4 \mathrm{ml} / \mathrm{min}$. The total run time was $13 \mathrm{~min}$. The gradient started with $95 \%$ of solvent A and $5 \%$ of solvent B at a ramp of curve 6 . At $8 \mathrm{~min}$, it shifted to $98 \%$ solvent B and $2 \%$ solvent $\mathrm{D}$ and stayed until $11 \mathrm{~min}$. From $12 \mathrm{~min}$, the gradient moved to its initial conditions of $95 \%$ of solvent $\mathrm{A}$ and $5 \%$ of solvent $\mathrm{B}$ at a ramp of curve 6 . The gradient mobile phase for CSH C18 column consisted of solvent A (50\% water and $50 \%$ acetonitrile with $0.1 \%$ formic acid), solvent B (90\% isopropanol with $10 \%$ acetonitrile and $0.1 \%$ formic acid). The column temperature was set to $65^{\circ} \mathrm{C}$ and flow rate of $0.45 \mathrm{ml} / \mathrm{min}$. The total run time was $11 \mathrm{~min}$. The gradient started with $60 \%$ of solvent $\mathrm{A}$ and $40 \%$ of solvent B. At 8 min, it shifted to $100 \%$ solvent B until 9 min and then back to its initial conditions. The gradient mobile phase for HSS T3 column consisted of solvent A $(100 \%$ water with $0.1 \%$ formic acid) and solvent B (100\% methanol with $0.1 \%$ formic acid). The column temperature was set at $45^{\circ} \mathrm{C}$ and flow rate of $0.4 \mathrm{ml} / \mathrm{min}$. The total run time was 13 min. The gradient started with $98 \%$ of solvent A and $2 \%$ of solvent B at a ramp of curve 6 . At $7.5 \mathrm{~min}$, it shifted to $10 \%$ solvent A and $90 \%$ solvent B and stayed until $9 \mathrm{~min}$. From $11 \mathrm{~min}$, the gradient moved to its initial conditions of $98 \%$ of solvent A and $2 \%$ of solvent B. The elution from the column was introduced to quadrupole timeof-flight mass spectrometer (G2-QTof, Waters Corp) by electrospray ionization at a capillary voltage of $3.0 \mathrm{kV}$ for positive mode and $1.5 \mathrm{kV}$ for negative mode. The sampling cone voltage was set at $30 \mathrm{~V}$ and the extraction cone at 3.0. The source temperature was set at $120^{\circ} \mathrm{C}$ and desolvation temperature at $500{ }^{\circ} \mathrm{C}$. The cone gas flow was maintained at $25 \mathrm{l} / \mathrm{h}$ and desolvation gas flow at $1000 \mathrm{l} / \mathrm{h}$. Leucineencephalin solution in $50 \%$ acetonitrile at a concentration of $2 \mathrm{ng} / \mu \mathrm{l}$ was used as a reference mass $([\mathrm{M}+\mathrm{H}]+=$ 556.2771 and $[\mathrm{M}-\mathrm{H}]-=554.2615)$. The data were acquired in centroid mode from mass range of 50-1200 with the software Mass lynx (Waters Corp). Pooled quality controls samples were injected after every ten injections. In addition, protein quantification was performed using Bradford protein analysis. Centroided and integrated mass spectrometry data from the UPLC-TofMS were processed using XCMS (Scripps Institute) to generate a data matrix containing ion intensities, mass to charge $(\mathrm{m} / \mathrm{z})$ and retention time values. Data were normalized to internal standard and protein content. Multivariate data analysis was performed using MetaboAnalyst (v4.0). The intracellular lactate levels were measured using the Lactate Colorimetric Assay Kit II (K627-100, BioVision; Milpitas, CA, USA). Cells $\left(2 \times 10^{6}\right)$ were homogenized with $200 \mu$ l of assay buffer by pipetting and pelleted by centrifugation $(2000 \mathrm{rpm}$ for $3 \mathrm{~min}$ ) at $4^{\circ} \mathrm{C}$. Then, $10 \mu \mathrm{l}$ of samples were transferred into 96-well plates and mixed with $40 \mu$ of assay buffer. Samples were incubated for $30 \mathrm{~min}$ at room temperature after $50 \mu \mathrm{l}$ of reaction mix was added, and absorbance (450 $\mathrm{nm})$ was measured. The average zero standard was subtracted as a background from all readings.

\section{Statistics}

Analyses were performed with GraphPad Prism software version 6.0c for Mac (GraphPad; San Diego, CA, USA), and details for analysis are included in figure legends. Data are expressed as the mean \pm s.d. and statistical significance was determined by Student's $t$ test or ANOVA test. $P$ value $<0.05$ were considered as significant.

\section{Results}

\section{Knockin of Gtf2i mutation results in cell transformation and tumor formation}

The limited availability of primary human TEC lines together with the presence of pseudogenes of GTF2I in the 
a
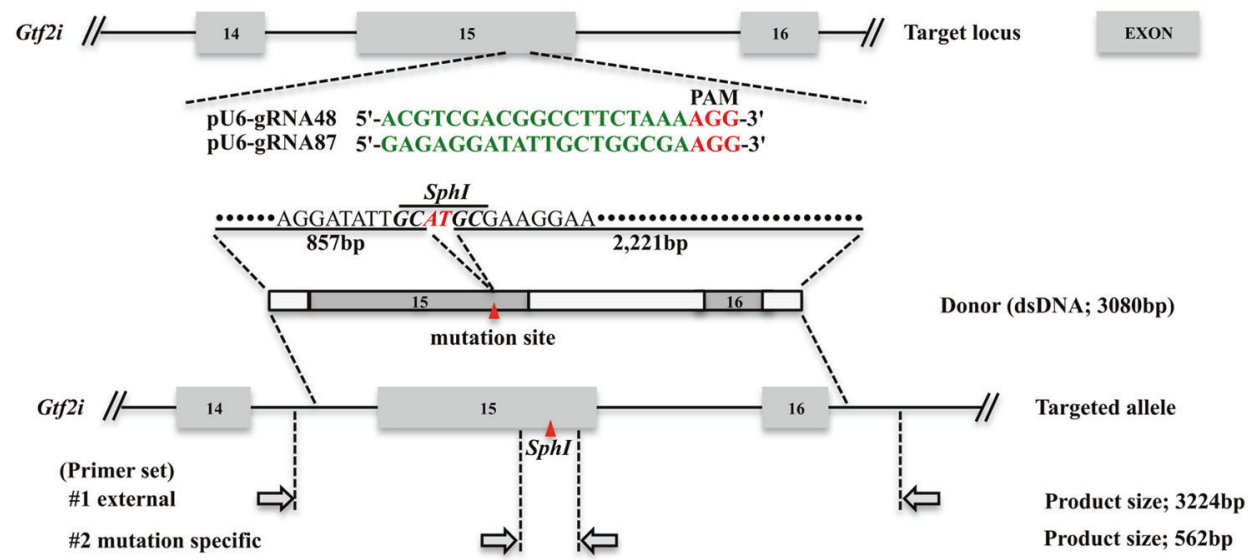

b
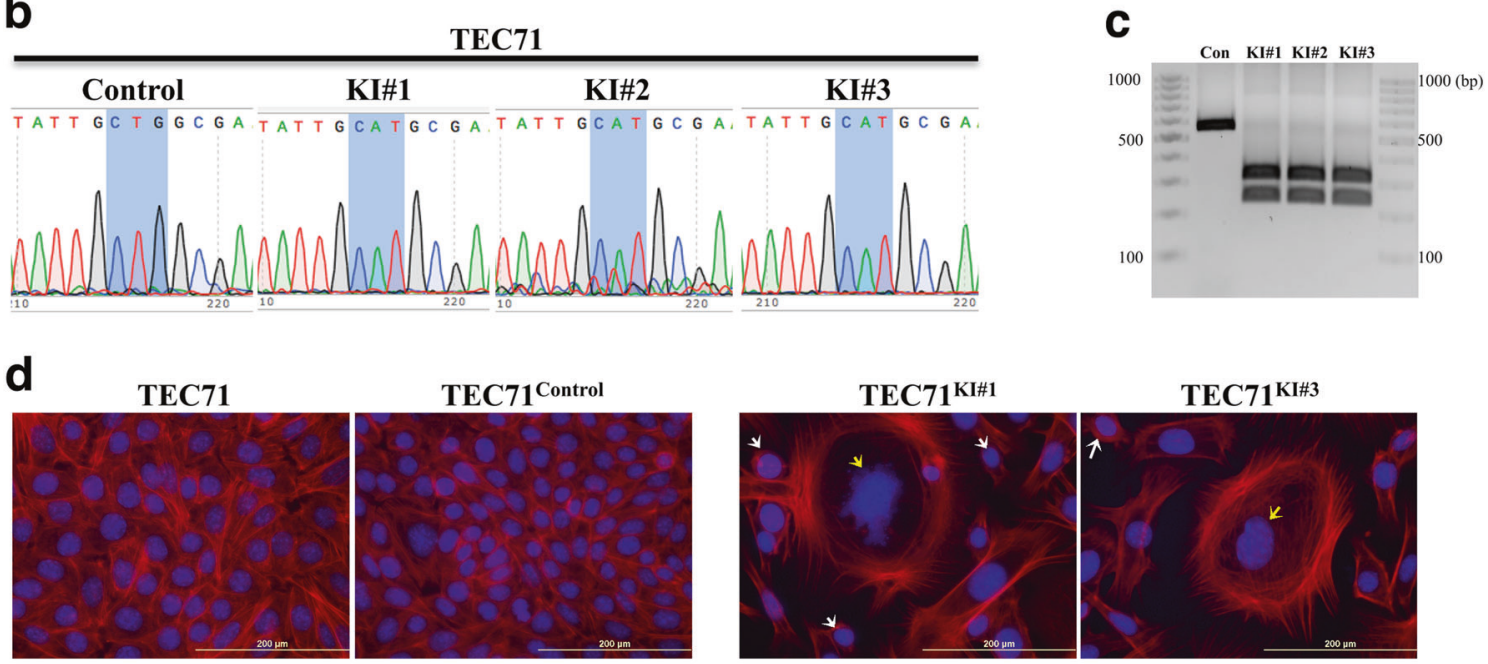

e
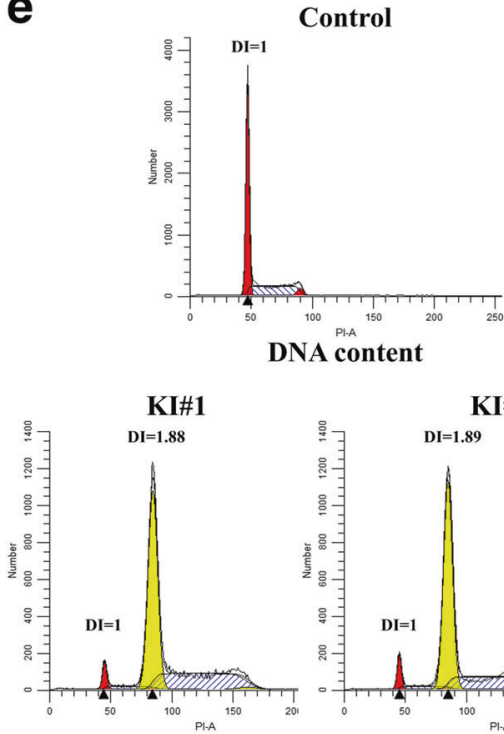

DNA content

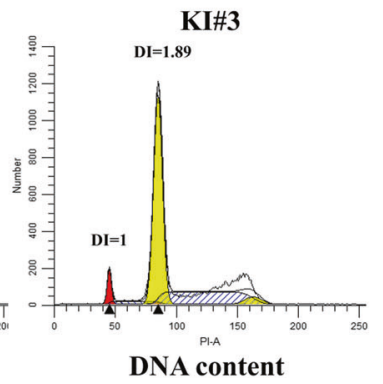

human genome, have limited an in depth understanding of the mechanisms of action of GTF2I. Given that mouse cells express only the $\beta$ and $\delta$ isoforms of Gtf2i [14], and that f

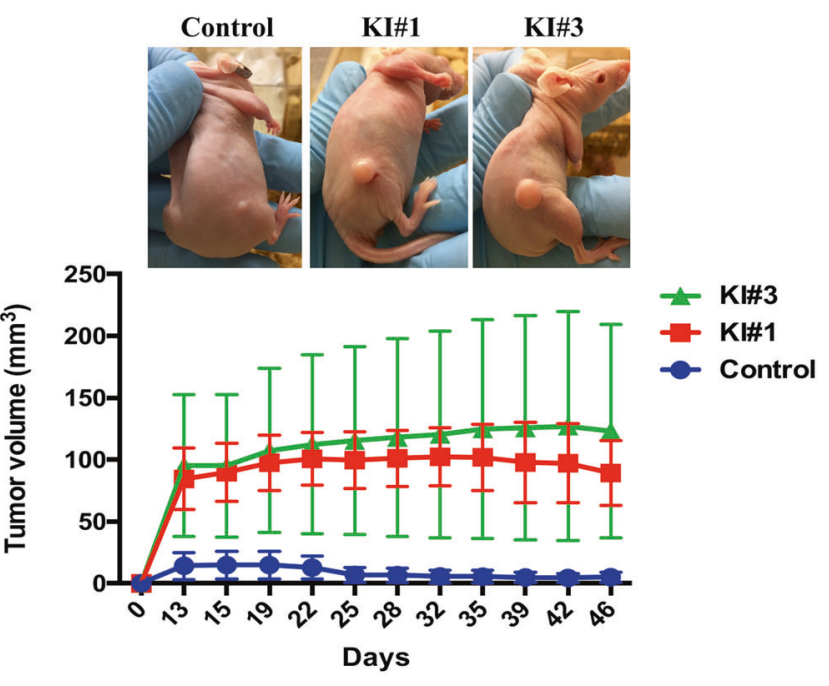

there are no pseudogenes, we used the CRISPR/Cas9n system for targeted mutational $\mathrm{KI}$ as well as to minimize off-target effects [15], in order to examine the function of 
Fig. 1 Cell transformation and in vivo tumorigenic effect of $G t f 2 i$ mutation. a Strategy to knockin Gtf $2 i$ mutation in TEC71 using CRISPR/Cas9n. The Gtf2i-specific guide RNA (pU6-gRNA) sequences are in green, and the protospacer-adjacent motif (PAM) sequence is shown in red. The targeted allele is replaced with double-strand DNA template donor containing SphI restriction enzyme site (bold italic) and two point mutations (red). A red arrowhead indicates the mutation site of Gtf2i. PCR with outward primers (\#1) and inward primers (\#2) sequentially amplified the genomic region of $G t f 2 i$ to verify KI. b Point mutations (CTG to CAT) of Gtf2i identified by Sanger sequencing. TEC71 cells transfected with Cas9n and one gRNA were used as control. c DNA fragmentation by SphI enzyme was used to verify the correct replacement of $G t f 2 i$ gene with mutation. One microgram of PCR amplified DNA with primer set \#2 was incubated with SphI for $3 \mathrm{~h}$ and DNA fragments ( 317 and $245 \mathrm{bp}$ ) were analyzed using $2 \%$ agarose gel electrophoresis. d Cytoskeleton and cell nuclei were stained with Texas Red-X phalloidin and DAPI, respectively, to enable observation of morphological changes. Arrows indicate cellular shape changes associated with cancer: irregular nuclear contour with polylobulation (yellow) or scant cytoplasm (white). Scale bars, $200 \mu \mathrm{m}$. e DNA-ploidy flow cytometric analysis of KI cells. f In vivo xenograft experiment of KI cells and control cells. Tumor volume $(P<0.0001)$ is presented as the means \pm s.d. $(n=10$ mice in each group). Statistical significance was determined by twoway ANOVA.

the GTF2I mutation (L424H). We established three KI clones of Gtf2i mutation, using a novel strategy (see "Methods"; Fig. 1a and S1A) in TEC71 mTECs. Sanger sequencing and enzyme digestion were performed to confirm precise substitution (CTG > CAT) and insertion of SphI site in the targeted alleles, respectively (Fig. 1b, c). The KI cells displayed an irregular size compared with control cells: the average diameter of control cells was $10.2 \mu \mathrm{m}$ and $99 \%$ of the cells were measured at $5.5-15.0 \mu \mathrm{m}$. The average diameter of KI cells was $14.8 \mu \mathrm{m}$ and most of the cells were larger in diameter than control cells $(88.6 \% 10.1-20.0$ $\mu \mathrm{m}$ and $7.6 \% 20.1-30.0 \mu \mathrm{m}, P<0.001$ unpaired $t$ test) (Fig. S1B). KI cells displayed altered morphology (spindleshaped elongation, and enlarged cell size) and nuclear shape with chromosomal aneuploidy (Fig. 1d, e and S1C), features which are characteristic of cellular transformation. We then evaluated the tumorigenic potential of $G t f 2 i$ mutation in vivo. Unlike control cells, KI cells resulted in tumor formation in nude mice while no significant differences were detected in body weight (Fig. If and Table S2). Taken together, our results indicate that the Gtf $2 i$ mutation has oncogenic activity and is tumorigenic.

\section{Gene expression profiling of KI cells}

The gene expression profiles of KI cells were examined using expression microarray analysis; KEGG pathway analysis revealed that metabolic and cancer-related pathways were most enriched in KI cells (Fig. 2a-c and Table S3). These included several signaling pathways which are frequently overexpressed in cancer (i.e., VEGF,
Wnt, Hedgehog, and Notch); oncogenes, EMT-related, and antiapoptotic genes. Moreover, expression of genes known to be overexpressed in thymoma such as Fas, Vcam1, and Bcl2 [16, 17] were also observed (Table S4). Furthermore, the expression of genes encoding cell adhesion molecules, tumor suppressors, and cell death inducers was decreased in KI cells (Table S5). We confirmed an increase in VEGF/ Wnt/Notch signaling, EMT regulators, oncogenes, antiapoptotic genes, and a decrease (cell adhesion related genes) in KI cells, using qRT-PCR, (Fig. 2d and S1D). At protein level $G t f 2 i$ mutation increased expression of VEGF signaling molecules, EMT-related molecules, and protooncogenes (Fig. 2e and S1E). Together, these results indicate that mtTFII-I-mediated transcriptomic alterations may contribute to tumorigenesis.

\section{mtTFII-I activates oncogenic pathways in cortical mTECs}

To determine whether Gtf $2 i$ mutation has same effect on cortical TECs, we established a doxycycline (Dox)-inducible system for mtTFII-I expression in TEC100.4 and TEC41.2 cells; because of high expression levels of TFII-I in all the five cell lines that we had available we did not overexpress wtTFII-I (Fig. 3a-c). Then we compared the gene expression profiles of TEC100.4 cells expressing either wtTFII-I (Dox untreated) or mtTFII-I (Dox treated); 3663 genes were identified by expression microarray analysis. Commonly regulated genes were mainly enriched in cancer pathways while mtTFII-I expression had little effect on metabolic pathway (Table S6), therefore we further narrowed down the list of potential targets to specific pathways involved in cancer by mtTFII-I. Expression of 48 genes was coregulated by TFII-I- $\beta \mathrm{mt}$ and TFII-I- $\delta \mathrm{mt}$ (Fig. 3d-f and Table S7-8). Of the 48 genes that are regulated in common, several proto-oncogenes were upregulated by mtTFII-I, similar to the KI cells (Fig. 2).

Protein levels of six proto-oncogenes were further examined by WB. Dox-induced TFII-I- $\delta m t$ increased c-fos protein levels, however different VEGFR2 expression patterns were detected in mTECs: VEGFR2 protein levels were increased by both isoforms of mTTFII-I in TEC41.2 but only by TFII-I- $\delta m t$ in TEC100.4. Although the mRNA level was positively regulated by mtTFII-I, WNT2B, and FGFBP1 protein levels were not significantly changed in two mTECs. In addition, c-myc expression was enhanced by mtTFII-I in TEC100.4 (2.1- and 1.4-fold by $\beta \mathrm{mt}$ and $8 \mathrm{mt}$, respectively) and in TEC41.2 (2.4- and 1.5-fold by $\beta \mathrm{mt}$ and Smt, respectively) (Fig. 3g). Consistent with the microarray and qRT-PCR results, c-kit protein levels were also elevated by mtTFII-I expression (Fig. 3h). It has been reported that $\beta$ and $\delta$ isoforms of GTF2I have distinct roles and subcellular localization, and extracellular stimuli such as serum 
a

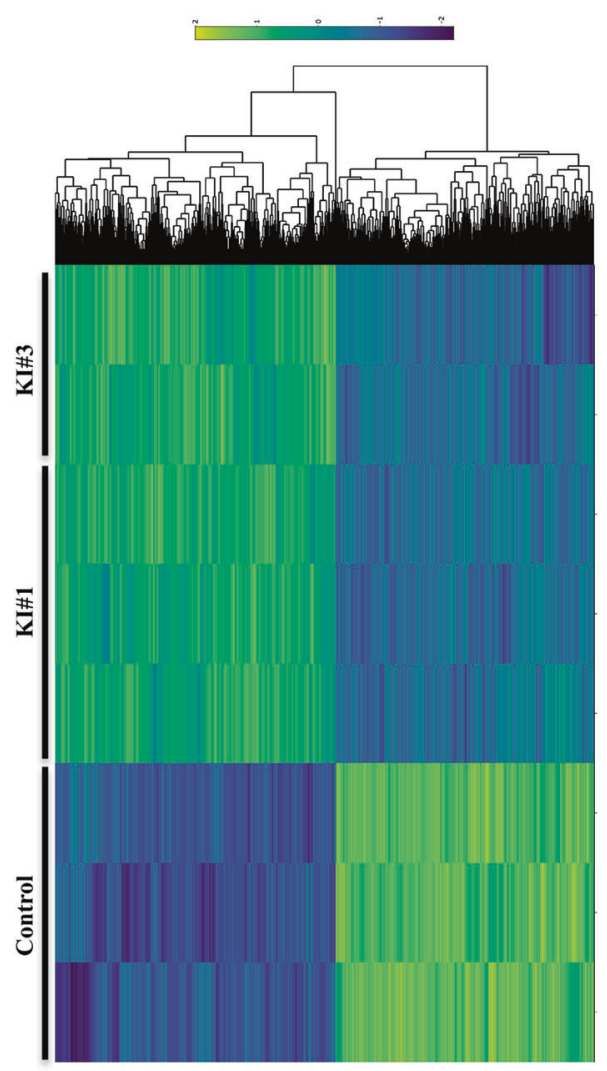

d
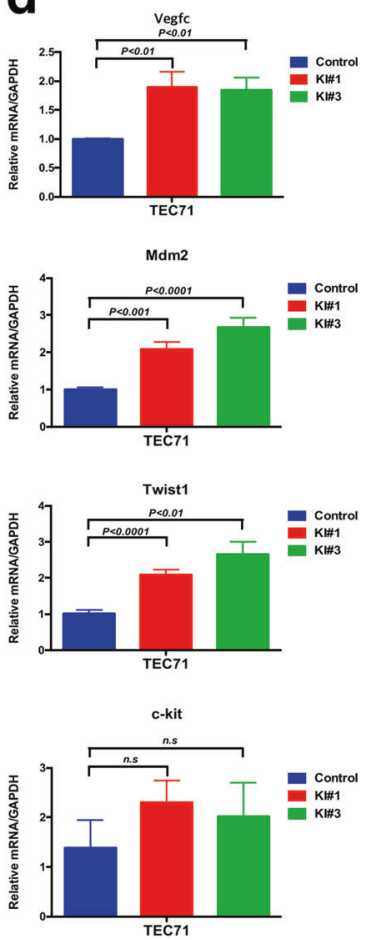
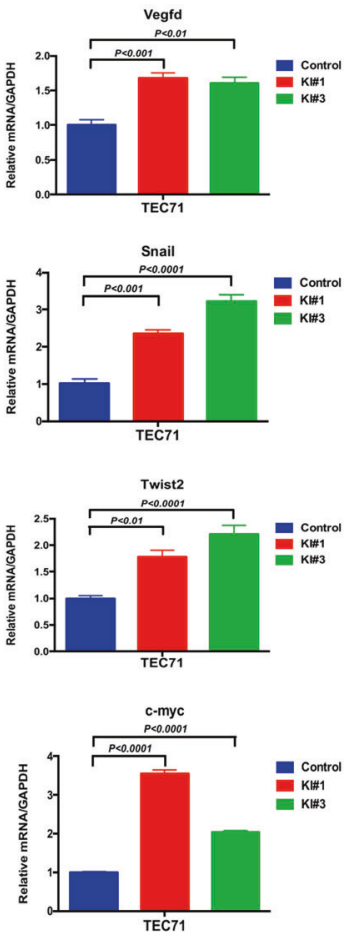

b

Pathway by KEGG of up-regulated genes

- Metabolic pathway Pathways in cancer - HTLV-I infection

- Purine metabolism " RNA transport

" Cell cycle

- Pyrimidine metabolism

- Spliceosome

" TNF signaling pathway

- NF-kB signaling pathway

- DNA replication

- Fanconi anemia pathway

"p53 signaling pathway

mRNA srveillance pathway

Glutathione metabolism

C

Pathway by KEGG of down-regulated genes

- Metabolic pathway " Endocytosis

" Pathway in cancer

" HTLV-I infection

- PI3K-Akt pathway

- Viral carcinogenesis

= MAPK pathway

- Lysosome

- Proteoglycans in cancer

- Phagosome

- Hippo pathway

Protein processing

- Foxo pathway

Tuberculosis
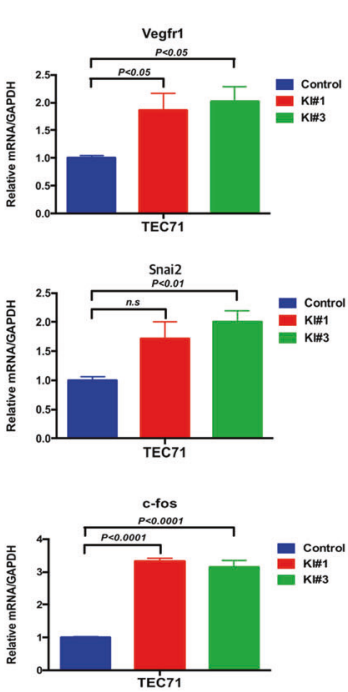

e

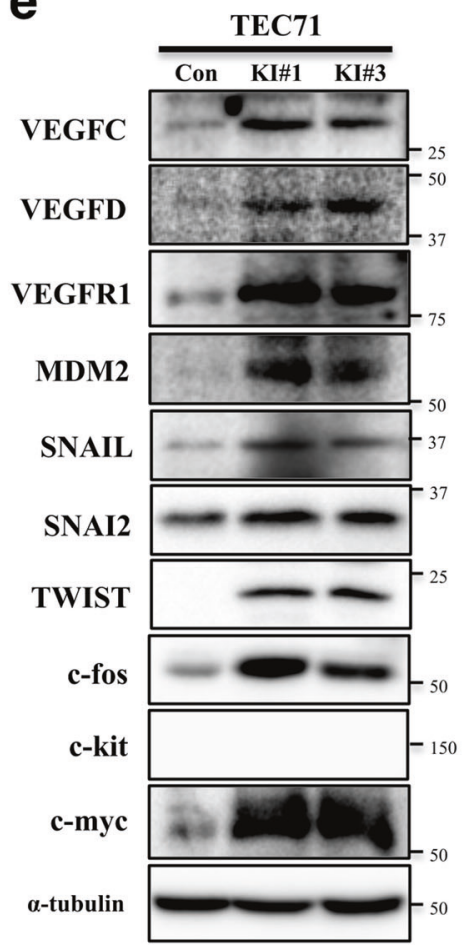

reverses localization of both isoforms [11]. However, similar to a previous report [14], we found no difference in the localization of ectopically expressed TFII-I proteins in both mTECs (cortical and medullary) and NIH-3T3 cells (Fig. S2A-C). These data demonstrate that mutant Gtf $2 i$ gene expression has the same effect on cortical TECs and 
Fig. 2 Oncogenic and EMT-related genes are increased by $G t f 2 i$ mutation. a Heatmap of differentially expressed 6528 genes from two KI cells compared with control cells. The data represent fold change of expression: increased expression (yellow), decreased expression (blue), no change (dark green). b, $\mathbf{c}$ The expression of 6528 transcripts overlapped in the profile. Pathway analysis by KEGG for upregulated (b) or downregulated (c) genes in common between KI\#1 and KI\#3 cells. d The mRNA expression levels of indicated genes determined by qRT-PCR and normalized by GAPDH expression. All data are means \pm s.d. from three independent experiments $(n=3)$, and statistical significance was determined by two-way ANOVA with Sidak's multiple comparisons test. n.s not significant. e Comparison for protein levels of ten selected genes between control and KI cells by WB analysis.

induction of oncogene expression by mtTFII-I that may be at the base of the potential tumorigenic activity of $G T F 2 I$ mutation.

\section{Gtf2i mutation confers survival advantage under glucose deprivation}

Given that metabolic pathway was strongly altered by $G t f 2 i$ mutation (Fig. 2) and the primary energy source for normal and tumor cells is glucose, we investigated whether $G t f 2 i$ mutation influences cell survival in different glucose concentrations. Although Gtf $2 i$ mutation decreased cell proliferation in normal $(11 \mathrm{mM})$ culture condition, KI cells continued to grow and demonstrated enhanced survival under no and low (1 and $5 \mathrm{mM}$ ) glucose conditions (Fig. 4a, b). Reduced glucose consumption based on low cell proliferation of KI cells may contribute to the sensitivity of glucose deprivation at early time points. No or low glucoseinduced apoptosis in control cells, as shown by cleavage of PARP and caspase-3, $\gamma \mathrm{H} 2 \mathrm{AX}$ expression, and increased sub-G1 fraction (29-59\%) while the expression levels of apoptotic markers and the sub-G1 cell populations were relatively low (5.7-28\%) in KI cells (Fig. 4c, d and S3A, B). The resistance to low glucose-induced apoptosis in $\mathrm{KI}$ cells was further confirmed by TUNEL and FACS analysis (Fig. 4e, f and S3C, D). These results indicate that $G t f 2 i$ mutation promotes mTECs survival under metabolic stress condition.

\section{Metabolic reprogramming in $\mathrm{KI}$ cells by activation of glycolysis and altered lipid biosynthesis}

Cancer cells exhibited different metabolic patterns compared with normal cells, at least in part manifested as enhanced glucose metabolism, aerobic glycolysis, lactate production, and high lipid metabolic activities [18]. In order to obtain better insight into $G t f 2 i$ mutation-induced metabolic shift under normal and glucose-limited condition, we performed metabolic profiling using LC/MS. In total, 17,512 and 21,005 metabolites were altered in two KI cells compared with control cells. The major difference between KI cells cultured in normal vs low glucose was in lipids (CSH column, right middle) (Fig. 5a) while only a few glycolysis and TCA cyclerelated metabolites were detected by LC/MS (Table S9A). Metabolite set enrichment analysis demonstrated that the Gtf $2 i$ mutation induced marked intracellular metabolic changes (Fig. S4). In particular, the pathway of arachidonic acid (AA) and sphingolipid metabolism was significantly altered in KI cells as compared with controls regardless of cell culture condition (Fig. S5 and Table S9B-E). Western blot (WB) analysis in KI cells cultured under normal medium showed increased expression of four glycolytic enzymes: Hexokinase I, PFKFB2 (6-phosphofructo-2-kinase/fructose2,6-biphosphatase 2), PFKP (phosphofructokinase, platelet), and Enolase-2. Intriguingly, these enzymes were also induced in glucose-limited conditions with the exception of Hexokinase I (Fig. 5b). The levels of lactate, the end product of glycolysis, were increased regardless of glucose concentration in KI cells (Fig. 5c). Glucose also supports fatty acid (FA) production through the synthesis of citrate and its conversion to acetyl-coenzyme A, the major precursor of lipid biosynthesis. Not only AA, which is polyunsaturated FA, but also many different types of lipids, including eicosanoids and sphingolipids, can be generated from FA [19]. AA is converted into prostaglandins by cyclooxygenases $(\mathrm{COX})$, and we found that $\mathrm{COX}-2$ levels were upregulated in $\mathrm{KI}$ cells irrespective of the culture conditions (Fig. 5b). Viewed collectively, these results suggest that $G t f 2 i$ mutation activates glycolysis and enhances lipid content in mTECs (Fig. 5d).

\section{COX-2 is essential for Gtf2i mutation-induced cell survival and transformation}

We generated stable KD cell lines to investigate the role of PFKFB2 and COX-2 in survival under metabolic stress. No or low glucose-induced apoptosis in two COX-2 KD cells, as shown by cleavage of PARP and caspase-3, $\gamma \mathrm{H} 2 \mathrm{AX}$ expression, marked increase of sub-G1 fraction and number of apoptotic cells (Fig. 6a-c and S6A-D), whereas cleavage of PARP and caspase-3 was not induced by PFKP or ENO2 $\mathrm{KD}$ in KI cells (Fig. S6E). Expression of apoptosis-related genes was only slightly induced by low glucose in PFKFB2 KD cells, and these cells did not exhibit evidence of apoptosis by flow cytometry analysis (Fig. 6a-c). Neither COX-2 nor PFKFB2 are required for survival under metabolic stress-induced apoptosis in control cells (Fig. S6F). Next, we investigated whether COX-2 or PFKFB2 is required for cellular transformation of $\mathrm{KI}$ cells induced by Gtf $2 i$ mutation in mTECs. COX-2 KD resulted in diminished actin formation and cells displayed typical epithelial morphology (Fig. 6d). Moreover, VIMENTIN and TWIST expression of KI cells was significantly decreased in COX-2 KD cells (Fig. 6e, f). In contrast, PFKFB2 KD had no effect 
a

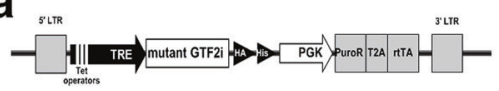

b

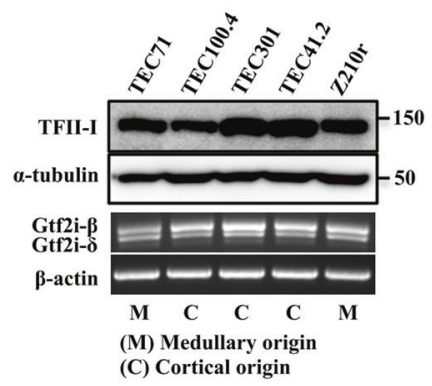

e

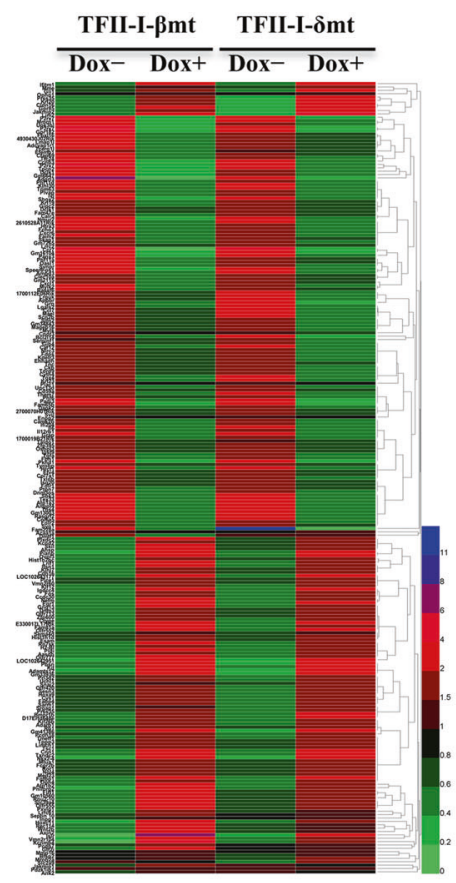

g

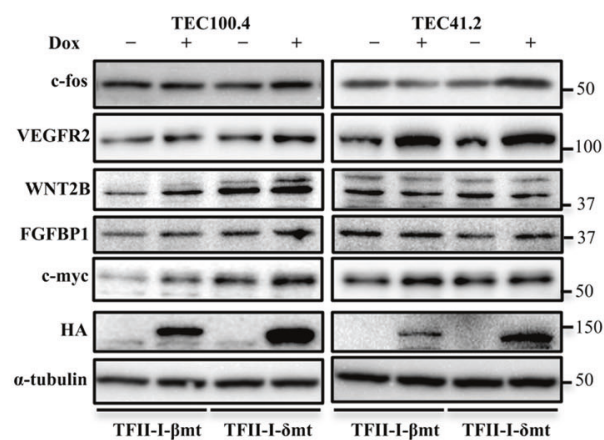

Fig. 3 Mutant TFII-I induces oncogene expression. a Diagram of the inducible expression system of pLIX402. b TFII-I protein level (upper panel) and mRNA level of $G t f 2 i-\beta$ and $-\delta$ isoforms (lower panel) in mTECs. c Cells were incubated with/without doxycycline (Dox) for $24 \mathrm{~h}$, and the inducible expression system was assessed by HA antibody. d Schematic representation of microarray anaylsis. e Heatmap of 235 differentially expressed genes between mtTFII-Iinducible TEC100.4 cells treated with/without Dox. The data represent

f

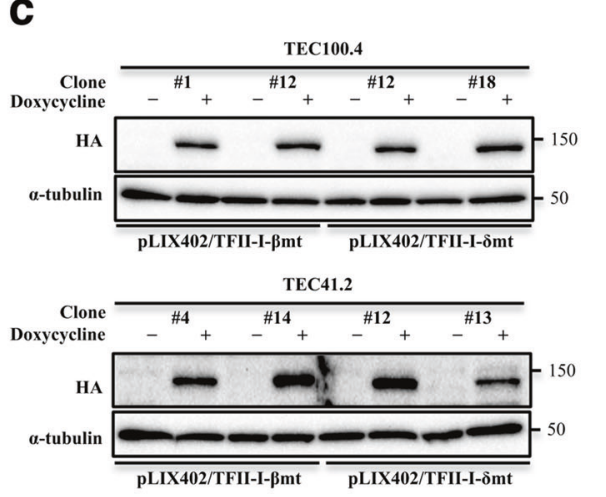

d

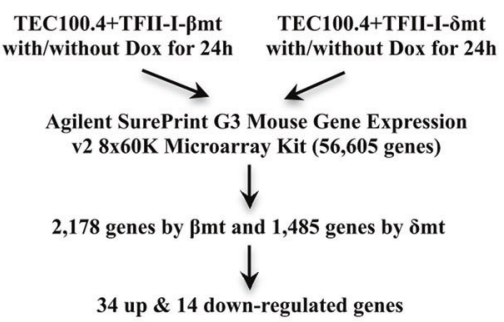

- Pathways in cancer

- cAMP signaling pathway

= Cytokine receptor interaction

- PI3K-AKT pathway

- Gastric acid secretion

- Insulin secretion

- Protein digestion and absorption

" cGMP-PKG pathway

" Calcium signaling pathway

- Hematopoietic cell lineage

- Circadian entrainment

" Pancreatic secretion

- Mineral absorption

Endocrine and calcium
reabsorption

h

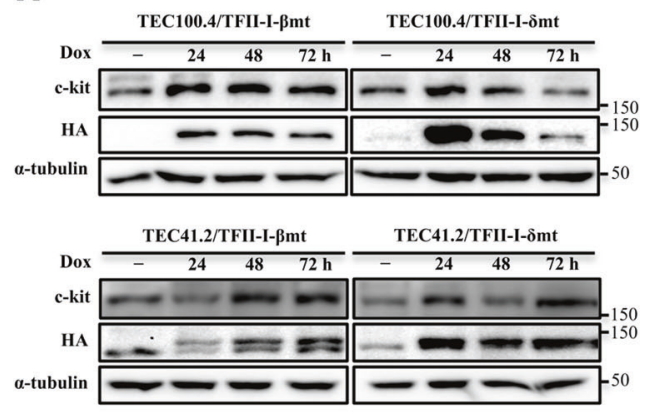

fold change of expression: increased expression (red and blue), decreased expression (green), no change (black). f Pathway analysis for 235 coregulated genes by TFII-I- $\beta$ and $-\delta m t$. g Cells were incubated with/without Dox for $24 \mathrm{~h}$ and protein levels were evaluated by WB analysis. ImageJ software was used to quantify signal intensity. $\mathbf{h}$ Dox-treated cells were harvested at indicated incubation time points and evaluated for c-kit levels by WB. 
a
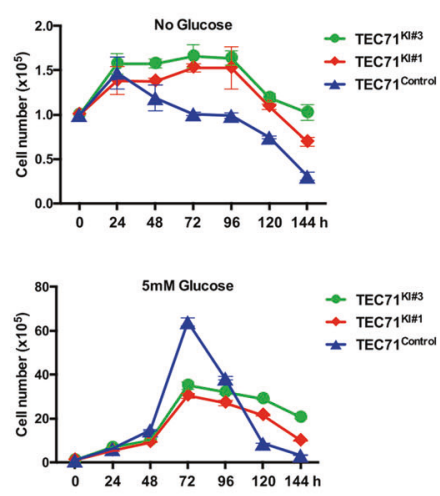

C

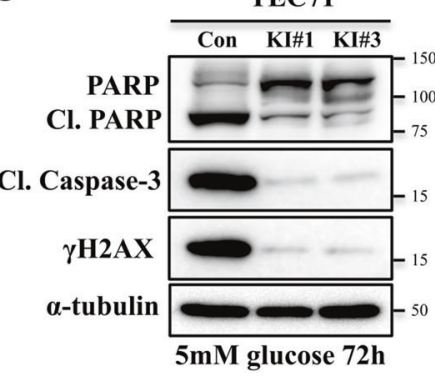

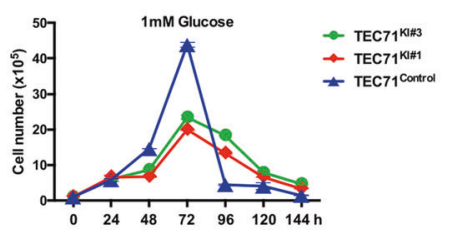

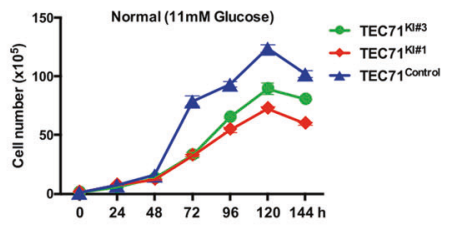

d

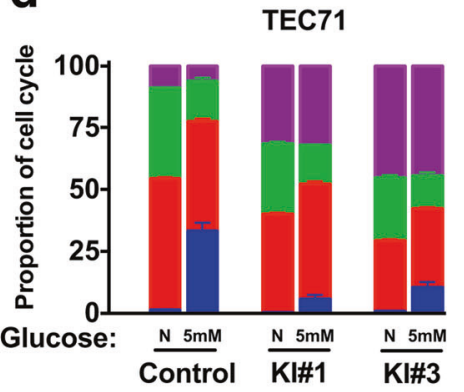

b

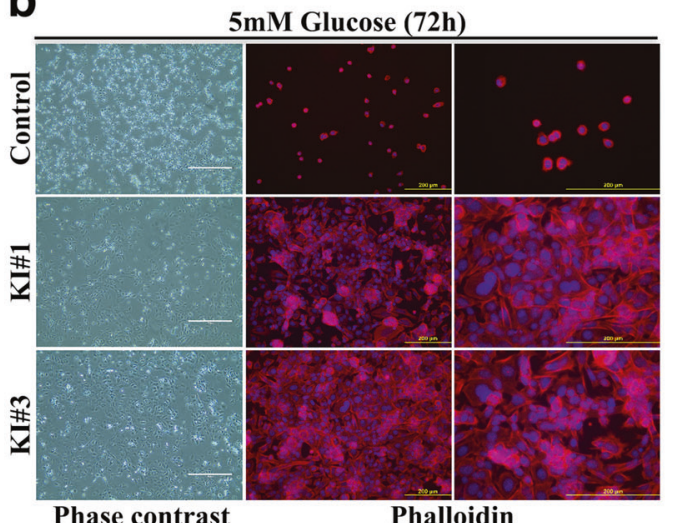

e

$\mathbf{f}$
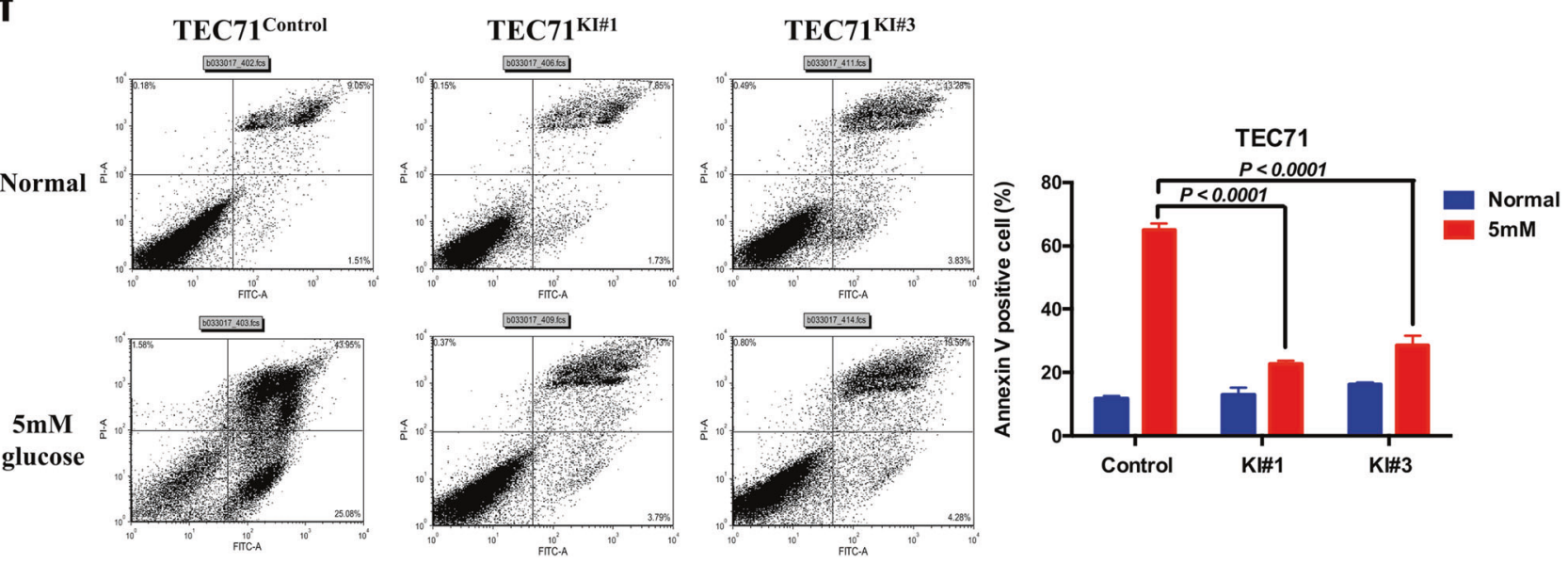

Fig. 4 Gtf $2 i$ mutation confers survival advantage under glucose deprivation. a Effect of $G t f 2 i$ mutation on the proliferation of TEC71 cells under different glucose conditions. Cell numbers were determined with trypan blue at indicated time points. Error bars represent s.d. of three replicate samples. b Representative images of control and KI cells under low glucose examined with phase contrast microscopy using an EVOS imaging system (AMG) (left); immunofluorescence using Texas Red-X phalloidin (red) and counterstained with DAPI (blue) (right). Scale bar, 200-400 $\mu \mathrm{m}$. c WB analysis of

PARP, cleaved caspase- 3 , and $\gamma \mathrm{H} 2 \mathrm{AX}$ in KI cells. d Cells were grown in normal $(\mathrm{N})$ or low glucose $(5 \mathrm{mM})$ medium for $72 \mathrm{~h}$ and cell cycle distribution was determined by flow cytometry. e Representative histogram showing the percentage of apoptotic cells (TUNEL-positive cells; Fig. S3C). f Apoptotic rate was assessed by flow cytometry with Annexin V/PI staining in cells grown in normal or low glucose condition for $72 \mathrm{~h}$. Data are means \pm s.d. from three independent experiments $(n=3)$, and statistical significance was determined by two-way ANOVA. n.s not significant.

on morphology and VIMENTIN expression in KI cells while cells showed epithelial-like cell formation and a reduction of TWIST (Fig. $6 \mathrm{~d}-\mathrm{f}$ ). These results suggest that Gtf2i mutation promotes cell survival and induces cellular transformation through COX-2 expression in mTECs.

\section{Enhanced tolerance to DNA damage associated with Gtf2i mutation}

Since TFII-I is required for DNA translesion synthesis and increases DNA damage tolerance [20], we compared DNA 
a
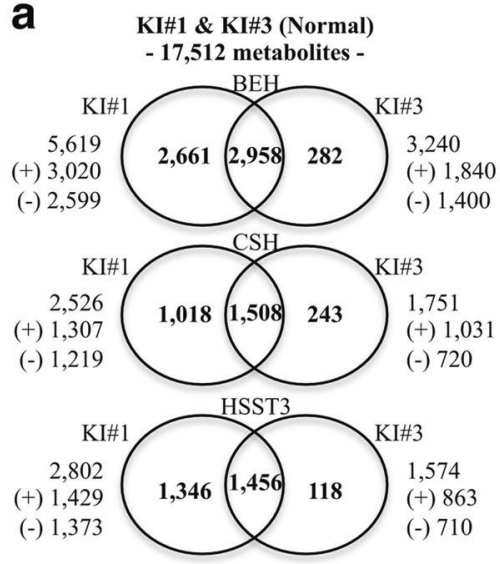

b

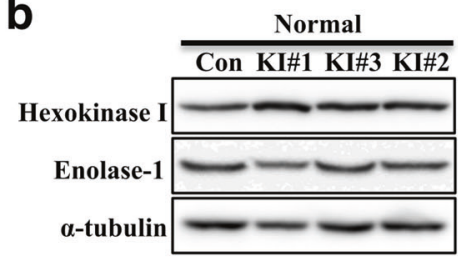

$5 \mathrm{mM} 72 \mathrm{~h}$

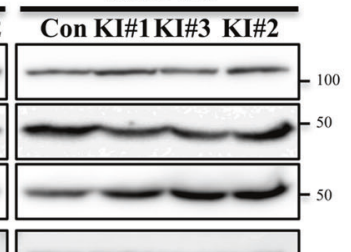

Hexokinase II $\square=$
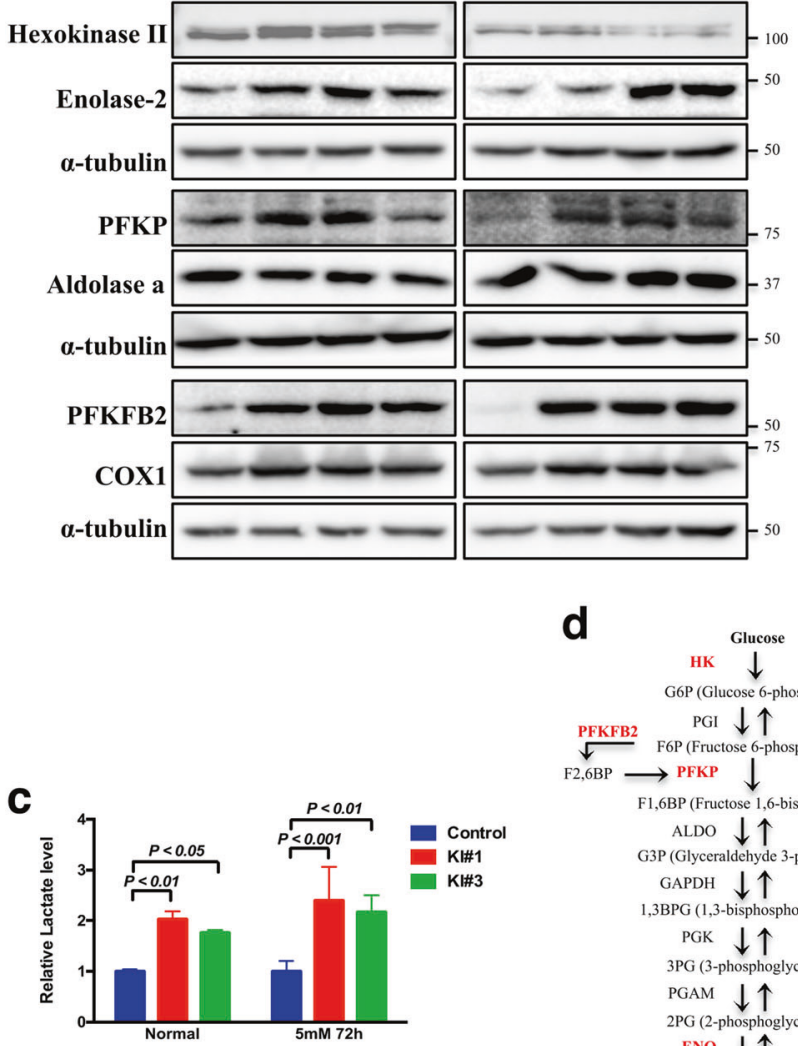

d

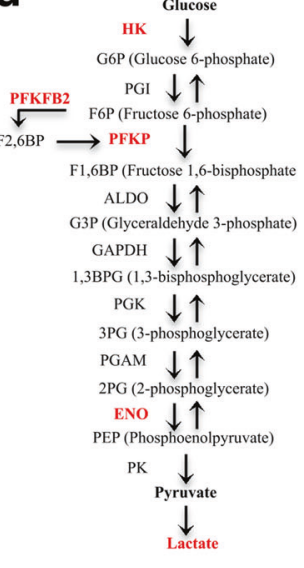

$$
\begin{aligned}
& \text { (Normal) }
\end{aligned}
$$

damage response to test whether mtTFII-I protects cells from DNA damage-induced apoptosis. KI cells were more resistant to UV-mediated (4-12 J/m²) cell death and showed
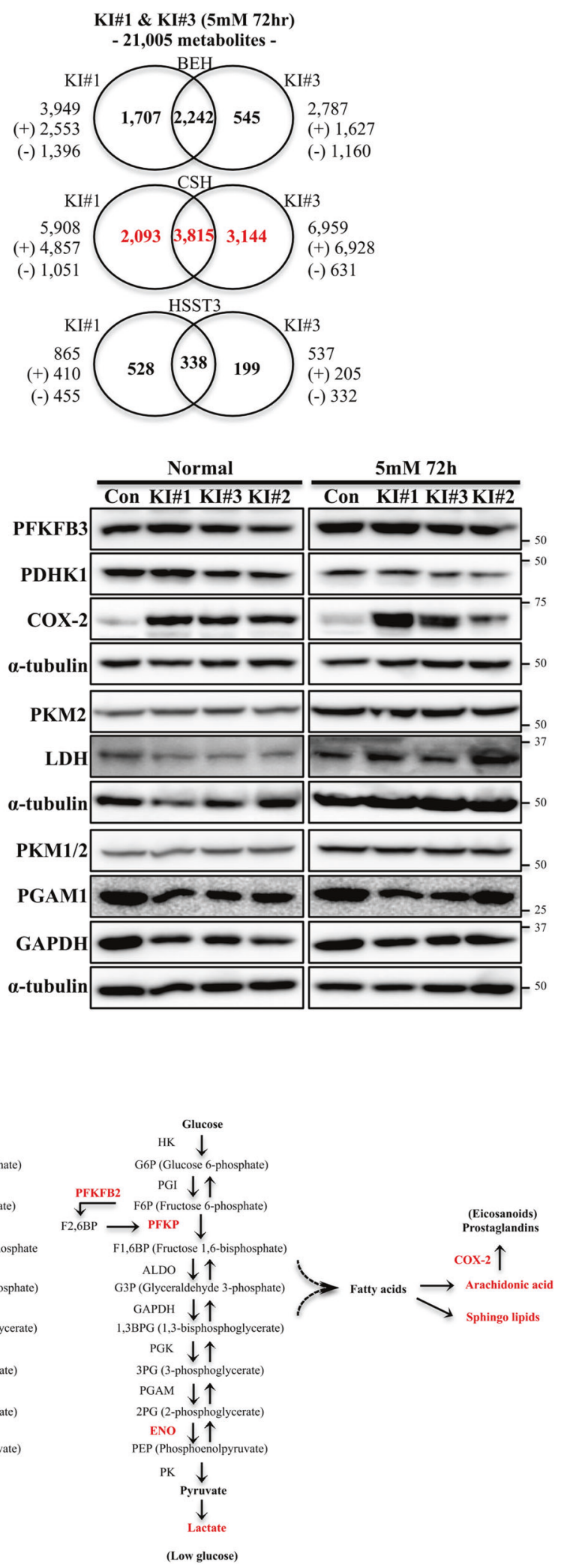

better survival than control cells (Fig. 7a, b and S7). To obtain further evidence for the role of Gtf2i mutation in DNA damage response, cells were exposed to cisplatin or 
Fig. $5 \mathrm{Gtf2i}$ mutation leads to metabolic reprogramming in mTECs. a Venn diagram of differentially expressed metabolites identified by different detection columns (BEH, CSH, and HSST3) and mode $(+$ or -$)$ in KI cells. b WB analysis was used to investigate enzymes involved in glycolysis. c Relative intracellular lactate levels in KI cells grown under different glucose concentrations. Data are means \pm s.d. from three independent experiments $(n=3)$, and statistical significance was determined by two-way ANOVA with Sidak's multiple comparisons test. d Identified metabolic changes (red) by Gtf $2 i$ mutation.

doxorubicin treatment and KI cells were more resistant compared with control cells (Fig. 7c). Different DNAdamaging sources induced the expression of apoptotic markers (cleaved PARP/Caspase- 3 and $\gamma \mathrm{H} 2 \mathrm{AX}$ ) in control cells but less in KI cells, with the exception of $\gamma \mathrm{H} 2 \mathrm{AX}$ expression induced by doxorubicin, which is known to inhibit the progression of topoisomerase II (Fig. 7d). DNA damage activates the tumor suppressor p53 and causes cell cycle arrest to trigger apoptosis. We observed that both total p53 and phospho-p53 (Ser15) levels in KI cells were increased more than in control cells by UV, cisplatin, and doxorubicin (Fig. 7e). KI cells also expressed high levels of p21, a cell cycle inhibitor, than control cells exposed to DNA damage whereas such differences were not observed for $\mathrm{p} 16$. Because transcription of the antiapoptotic regulator Bcl2 was increased in KI cells (Fig. S1D and Table S4), we therefore examined whether antiapoptotic genes can be induced by DNA damage in KI cells. KI cells expressed higher levels of $\mathrm{Bcl} 2$ and $\mathrm{Bcl}-\mathrm{xL}$ in response to $\mathrm{UV}$, cisplatin, and doxorubicin treatment, compared with control cells (Fig. 7e). Together, these results suggest that Gtf $2 i$ mutation confers a survival advantage to DNA damageinduced cell death in mTECs.

\section{Discussion}

Here we have demonstrated that mtTFII-I induces the expression of oncogenes, of several glycolytic enzymes, lactate production, and AA metabolism are positively regulated by $G t f 2 i$ mutation. Gtf $2 i$ mutation caused cellular transformation, aneuploidy, and tumorigenicity in vivo, and conferred a survival advantage against nutrient deprivation and DNA damage. We also present evidence that COX-2 expression is required for cellular transformation and survival of mTECs induced by Gtf2i mutation. Based on these findings, we propose that GTF2I L424H mutation is an oncogenic driver mutation responsible for the initiation of tumorigenesis in TECs (Fig. S8).

Several transcription factors have been identified to be oncogenic through fusion with other proteins, or deregulated expression due to mutations [21]. However, there are very few tumors that are characterized by one dominant genetic abnormality [22]. GTF2I has been studied mainly in relation to a genetic syndrome (Williams-Beuren), autoimmune diseases, and embryonic development [9], while only a few studies have identified an association with cancer with substantial experimental evidence, to date. In previous studies we have shown that higher c-fos expression is detected in human TETs that harbor GTF2I mutation than GTF2I wild type, and the GTF2I Leu > His may augment its activity or gain novel functions by recruiting new interaction partners [7]. In addition, myc was found to be highly expressed in mouse thymic tumors [23]. In the present study, we found that both mRNA and protein levels of $c$-fos and $c$-myc are upregulated by mtTFII-I. Structural chromosomal abnormalities and aneuploidy are well-defined characteristics of cancer and can predispose to tumor development [24]. EMT is an essential morphologic transformation for cancer development and progression. Hognas et al. showed that aneuploidy facilitates oncogenic transformation via Twist2 [25], and high prevalence of aneuploidy was detected in thymoma [8]. In addition, type A and AB thymomas are strongly positive for vimentin [26] and Slug is overexpressed in 51\% (51/100) of thymoma tissues [27]. Similar to these reports, we observed higher levels of Twist, Snail, and Vimentin expression in GTF2I mutant thymomas than GTF2I wild-type thymomas by RNA-seq; our observation in transcriptional changes is consistent with transcriptional differences in human thymic tumors according to the presence/absence of GTF2I mutation (Fig. S9-10). Here, we showed that Gtf $i$ mutation causes severe aneuploidy and EMT in mTECs. Furthermore, both $c$-fos and myc expressions are thought to contribute to transformation of TECs [28], indicating that GTF2I mutation is the earliest driving force for tumor development through chromosomal instability and EMT.

Recent studies revealed that dysregulated metabolism is associated with EMT, and metabolic reprogramming has been observed in relation to mutations in oncogenes or tumor suppressors, and altered energy metabolism is a hallmark of cancer [29, 30]. Prostaglandins are a group of lipids derived from the sequential oxygenation of AA by COX-1 and COX-2: whereas COX-1 is diffusely expressed in most tissues, COX-2 is inducible and increased expression has been detected in various cancer cell types and tissues including all primary epithelial cancers. Although COX-2 is overexpressed in most TETs and in the medullary epithelial cells only [31], the underlying molecular mechanisms by which COX-2 expression is regulated in TETs remain unclear. Numerous functional regulatory elements were identified in the human and mouse COX-2 gene promoters, including cyclic AMP response element, sterol response element, CAAT enhancer binding protein motif, SP1/NF-kB/AP-1 site, E-box, and TATA box [32]. TFII-I interacts with the E-box that is recognized by USF 
a

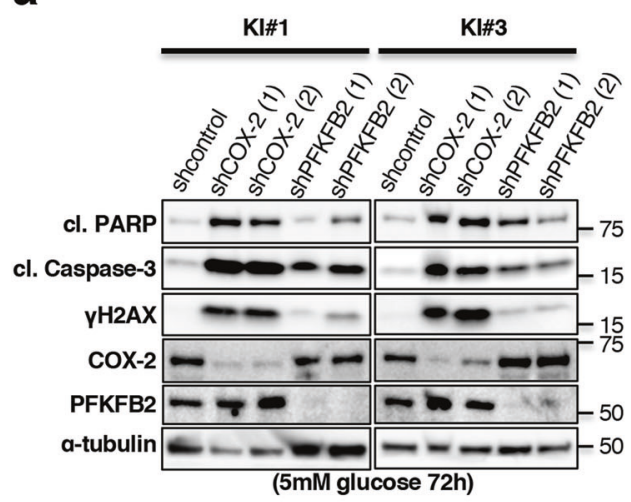

b

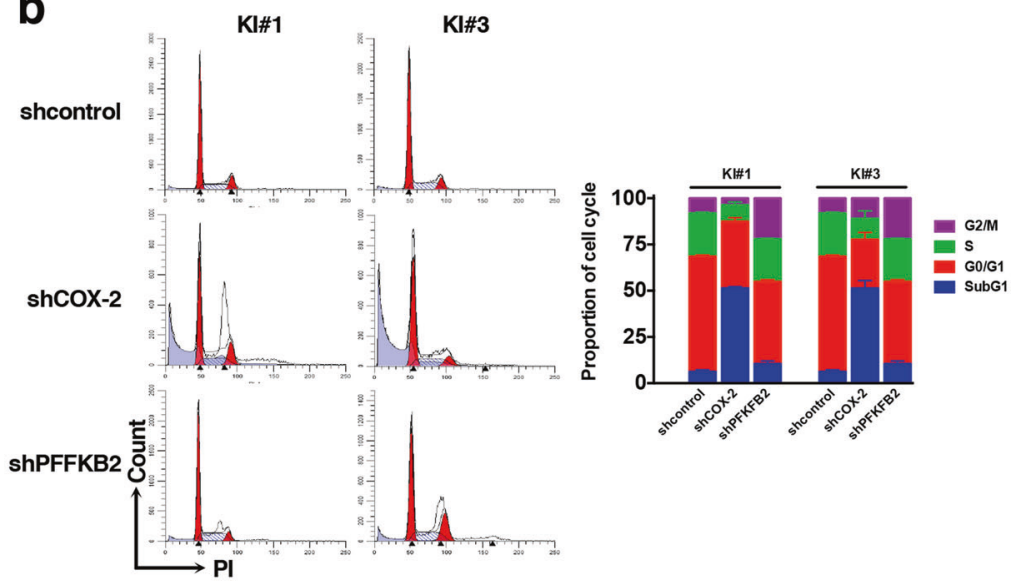

C
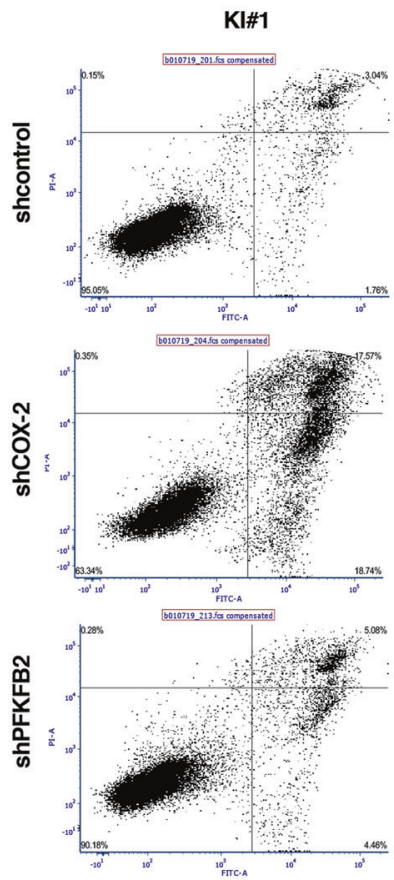

e

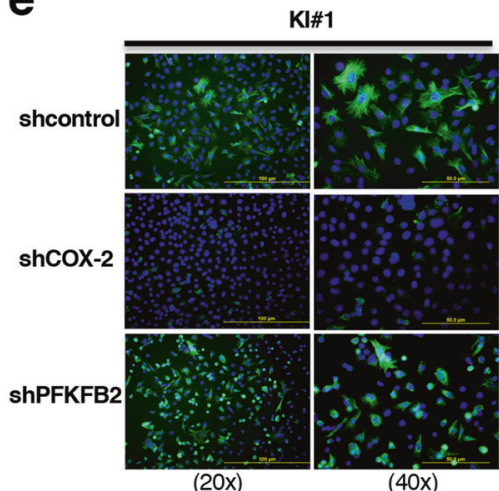

(20x)
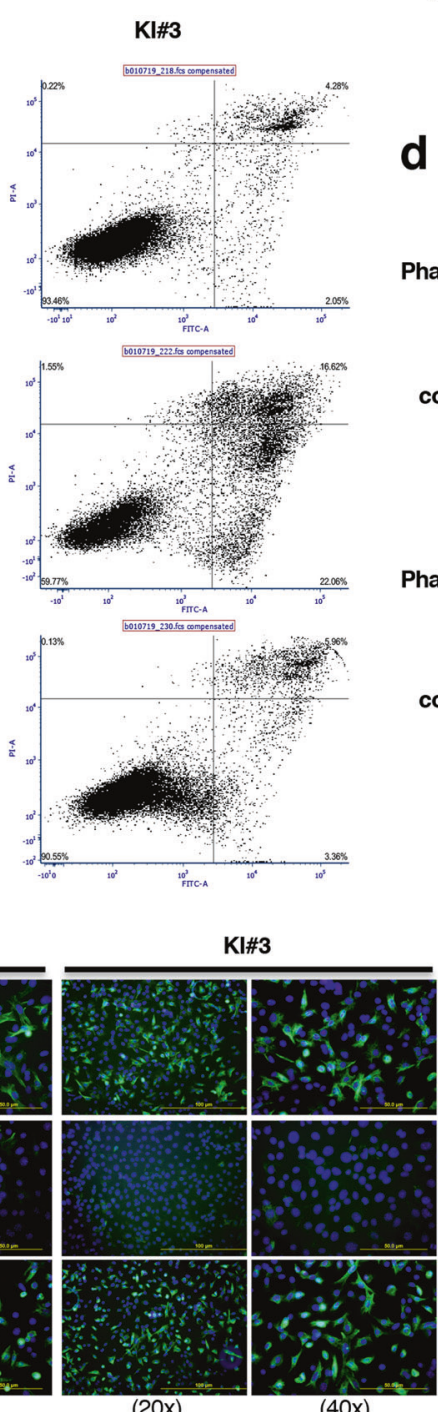

d

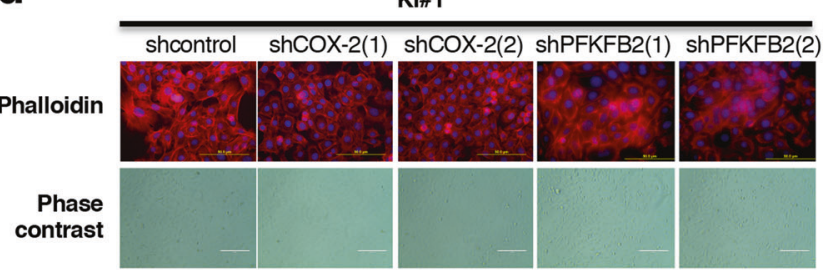

$\mathrm{Kl} \# 3$

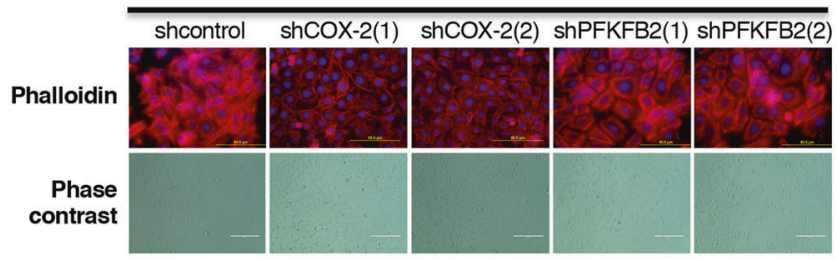

f

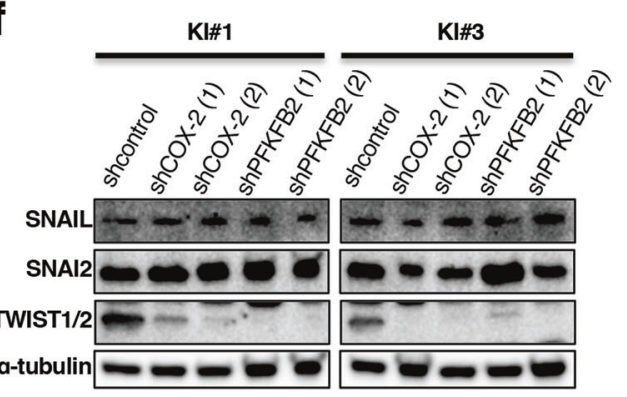

(upstream transcription factor) and TFII-I was identified as part of a co-regulatory protein complex with $\mathrm{Sp} 1 / 3$ and USF1 that represses the SSeCKS gene expression [11, 33]. Because Sp1 site is close to the E-box element at position $-52 /-47$ in the mouse $\mathrm{COX}-2$ promoter in the
TRANSFAC database, it is conceivable that COX-2 gene expression might be regulated by mtTFII-I through similar mechanisms as described for SSeCKS gene expression. COX-2 favors tumorigenesis by promoting angiogenesis, cell proliferation, activation of transcription factors that 
Fig. 6 COX-2 contributes to cell survival and transformation mediated by $\boldsymbol{G t} f \mathbf{i}$ mutation. a Cells were grown in low glucose ( 5 $\mathrm{mM}$ ) medium for $72 \mathrm{~h}$ and protein levels were evaluated by WB. b Cells were grown in low glucose $(5 \mathrm{mM})$ medium for $72 \mathrm{~h}$ and cell cycle distribution was determined by flow cytometry (left), the percentage in each phase of the cell cycle is shown (right). Data are means \pm s.d. from three independent experiments $(n=3)$, and statistical significance was determined by two-way ANOVA. c Apoptotic rate was assessed by flow cytometry with Annexin V/PI staining in cells grown in low glucose $(5 \mathrm{mM})$ condition for $72 \mathrm{~h}$. d Representative images of KD cells stained with Texas Red-X phalloidin (red) and DAPI (blue). Cell images under normal culture dish are observed by phase contrast microscope. Scale bar, $50 \mu \mathrm{m}$ (palloidin) or $200 \mu \mathrm{m}$ (phase contrast). e Immunostaining for VIMENTIN (green), DAPI was used for nuclear staining (blue). Scale bars, $100 \mu \mathrm{m}(20 \times)$ or $50 \mu \mathrm{m}(40 \times)$. f WB analysis for SNAIL, SNAI2, and TWIST in COX-2 or PFKFB2 KD cell lines.

a
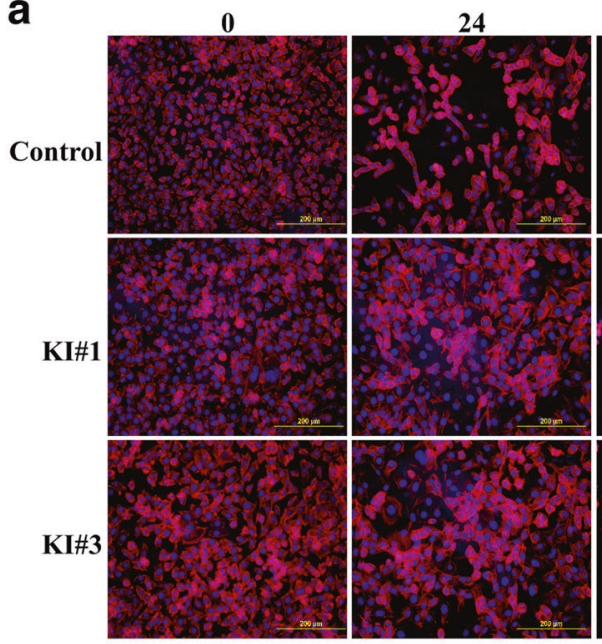

$U V-C\left(4 J / m^{2}\right)$

\section{d}
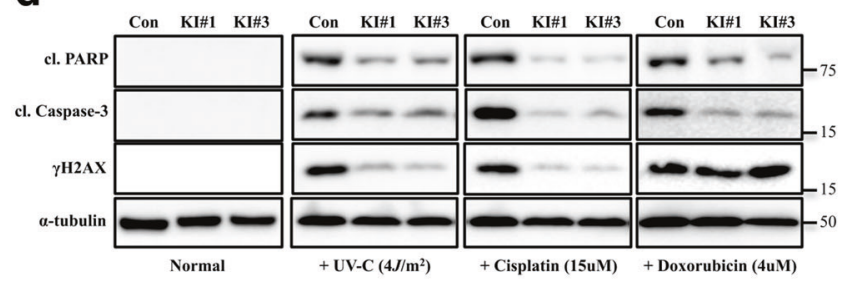

Fig. 7 Gtf $2 i$ mutation confers DNA damage resistance. a Representative images of control and KI cells under UV exposure stained with Texas Red-X phalloidin (red) and counterstained with DAPI (blue). Scale bar, $200 \mu \mathrm{m}$. b Cells $\left(5 \times 10^{5}\right)$ were plated in $6 \mathrm{~cm}$ dish and cell numbers were determined with trypan blue at indicated time points. Error bars represent s.d. of three replicate samples. c Cells were treated at indicated concentrations of cisplatin (upper panel) or doxorubicin (low panel) and cell viability was measured by the CCK-8 regulate EMT, and prevention of apoptosis [34, 35]. In line with this, we demonstrated that COX-2 is upregulated by Gtf $2 i$ mutation and speculated that alterations in the lipidic metabolism play a pivotal role in cell survival and carcinogenesis. Indeed, we discovered that $G t f 2 i$ mutation confers survival and transformation of mTECs through COX-2 and TWIST expression. Given that EMT is shown to control metabolic reprogramming [36], COX-2/TWISTinduced EMT is a possible mechanism in play in tumorigenesis of mTECs by Gtf $2 i$ mutation.

TFII-I connected DNA polymerase (Pol $\zeta$ ) to PCNA (proliferating cell nuclear antigen) and facilitated translesion synthesis; TFII-I depletion enhanced UV or cisplatin sensitivity, and ectopic TFII-I expression reduced DNA double-strand break in human cells [20]. DNA damage in response to oncogenic stress activated p53 and activation of 
p53-mediated transcription is a critical cellular mechanism of tumor suppression [37]. p21 has been shown to be regulated by $\mathrm{p} 53$-dependent and -independent mechanisms following stress and p21 expression caused cell cycle arrest. However, normal function of p21 was to protect thymic tumor cells against ionizing radiation and p21 was not essential for p53-dependent apoptosis in mouse thymocytes [38]. In addition, increasing evidence suggests that $\mathrm{p} 21$ is a negative regulator of apoptosis, through: (1) nuclear translocation and binding to chromatin-bound PCNA for DNA repair, (2) interaction of $\mathrm{p} 21$ with pro-apoptotic molecules in the cytoplasm [39]. Although the intracellular localization of p21 and p53 was not altered by DNA damage in KI cells (Fig. S11), our data led us to presume that mtTFII-I confers DNA damage resistance through antiapoptotic gene expression, DNA repair, or inhibition of p53 transactivity by MDM2 [40] in TECs. In keeping with our findings, pathway analysis demonstrated lower expression of genes involved in apoptosis, cell cycle, and DNA damage response in GTF2I mutant tumors compared with GTF2I wild-type tumors [8].

In summary, here we propose that GTF2I mutation can directly contribute to tumor formation in TECs. Since we have identified the missense mutation of GTF2I, other groups confirmed this specific mutation [41, 42] including TCGA project, which suggested to be a founder mutation occurring early in tumor development [8]. Moreover, thymus specific GTF2I L424H mutation was recently identified as one of 1165 statistically significant recurrent mutations in 24,592 human tumor samples [43]. Taken together, all our observations underscore the GTF2I mutation as a specific molecular marker for TETs. The study of the precise mechanisms by which mtTFII-I regulates target gene expression and the exact functional differences between TFII-I- $\beta m t$ and TFII-I- $\delta m t$ will need to be addressed.

Acknowledgements We acknowledge the assistance provided by the Flow Cytometry and Proteomics \& Metabolomics Shared Resource of Lombardi Comprehensive Cancer Center for FACS and Metabolomics. We would like to thank Dr. Uimook Choi (NIAID, NIH) and Jung-hyun Kim (NCI, NIH) for valuable discussions on CRISPR system. This work was supported by Lombardi Comprehensive Cancer Center grant (P30-CA051008 to GG).

Author contributions Conceptualization, I-KK, YW, Y-WZ and GG; methodology, I-KK, YW, and Y-WZ; validation, I-KK, GR and XZ; formal analysis, I-KK and RF; investigation and data curation, I-KK; writing —original draft, I-KK; writing - review and editing, I-KK, GR, XZ, RF, YW, MLA, Y-WZ and GG.

\section{Compliance with ethical standards}

Conflict of interest The authors declare that they have no conflict of interest.
Publisher's note Springer Nature remains neutral with regard to jurisdictional claims in published maps and institutional affiliations.

\section{References}

1. Engels EA. Epidemiology of thymoma and associated malignancies. J Thorac Oncol. 2010;5:S260-265.

2. De Jong WK, Blaauwgeers JL, Schaapveld M, Timens W, Klinkenberg TJ, Groen HJ. Thymic epithelial tumours: a populationbased study of the incidence, diagnostic procedures and therapy. Eur J Cancer. 2008;44:123-30.

3. Marx A, Chan JK, Coindre JM, Detterbeck F, Girard N, Harris NL, et al. The 2015 World Health Organization classification of tumors of the thymus: continuity and changes. J Thorac Oncol. 2015;10:1383-95.

4. Venuta F, Anile M, Diso D, Vitolo D, Rendina EA, De Giacomo $\mathrm{T}$, et al. Thymoma and thymic carcinoma. Eur J Cardiothorac Surg. 2010;37:13-25.

5. Scorsetti M, Leo F, Trama A, D'Angelillo R, Serpico D, Macerelli $\mathrm{M}$, et al. Thymoma and thymic carcinomas. Crit Rev Oncol Hematol. 2016;99:332-50.

6. Kelly RJ, Petrini I, Rajan A, Wang Y, Giaccone G. Thymic malignancies: from clinical management to targeted therapies. $\mathrm{J}$ Clin Oncol. 2011;29:4820-7.

7. Petrini I, Meltzer PS, Kim IK, Lucchi M, Park KS, Fontanini G, et al. A specific missense mutation in GTF2I occurs at high frequency in thymic epithelial tumors. Nat Genet. 2014;46:844-9.

8. Radovich M, Pickering CR, Felau I, Ha G, Zhang H, Jo H, et al. The integrated genomic landscape of thymic epithelial tumors. Cancer Cell. 2018;33:244-58 e210.

9. Roy AL. Pathophysiology of TFII-I: old guard wearing new hats. Trends Mol Med. 2017;23:501-11.

10. Hinsley TA, Cunliffe P, Tipney HJ, Brass A, Tassabehji M. Comparison of TFII-I gene family members deleted in Williams-Beuren syndrome. Protein Sci. 2004;13:2588-99.

11. Roy AL. Biochemistry and biology of the inducible multifunctional transcription factor TFII-I: 10 years later. Gene. 2012;492:32-41.

12. Chu VT, Weber T, Wefers B, Wurst W, Sander S, Rajewsky K, et al. Increasing the efficiency of homology-directed repair for CRISPR-Cas9-induced precise gene editing in mammalian cells. Nat Biotechnol. 2015;33:543-8.

13. Ran FA, Hsu PD, Wright J, Agarwala V, Scott DA, Zhang F. Genome engineering using the CRISPR-Cas9 system. Nat Protoc. 2013;8:2281-308.

14. Hakre S, Tussie-Luna MI, Ashworth T, Novina CD, Settleman J, Sharp PA, et al. Opposing functions of TFII-I spliced isoforms in growth factor-induced gene expression. Mol Cell. 2006;24:301-8.

15. Ran FA, Hsu PD, Lin CY, Gootenberg JS, Konermann S, Trevino $\mathrm{AE}$, et al. Double nicking by RNA-guided CRISPR Cas 9 for enhanced genome editing specificity. Cell. 2013;154:1380-9.

16. Park SH, Kim HK, Kim H, Ro JY. Apoptosis in thymic epithelial tumors. Pathol Res Pract. 2002;198:461-7.

17. Alexander M, Hans KM-H. Epithelial tumors of the thymus: pathology, biology, treatment. New York: Plenum Press; 1997.

18. Beloribi-Djefaflia S, Vasseur S, Guillaumond F. Lipid metabolic reprogramming in cancer cells. Oncogenesis. 2016;5:e189.

19. Baenke F, Peck B, Miess H, Schulze A. Hooked on fat: the role of lipid synthesis in cancer metabolism and tumour development. Dis Model Mech. 2013;6:1353-63.

20. Fattah FJ, Hara K, Fattah KR, Yang C, Wu N, Warrington R, et al. The transcription factor TFII-I promotes DNA translesion synthesis and genomic stability. PLoS Genet. 2014;10:e1004419.

21. Lee TI, Young RA. Transcriptional regulation and its misregulation in disease. Cell. 2013;152:1237-51. 
22. Tiacci E, Trifonov V, Schiavoni G, Holmes A, Kern W, Martelli MP, et al. BRAF mutations in hairy-cell leukemia. N Engl J Med. 2011;364:2305-15.

23. Conacci-Sorrell M, Ngouenet C, Anderson S, Brabletz T, Eisenman RN. Stress-induced cleavage of Myc promotes cancer cell survival. Genes Dev. 2014;28:689-707.

24. Gordon DJ, Resio B, Pellman D. Causes and consequences of aneuploidy in cancer. Nat Rev Genet. 2012;13:189-203.

25. Hognas G, Hamalisto S, Rilla K, Laine JO, Vilkki V, Murumagi A, et al. Aneuploidy facilitates oncogenic transformation via specific genetic alterations, including Twist2 upregulation. Carcinogenesis. 2013;34:2000-9.

26. Liu B, Rao Q, Zhu Y, Yu B, Zhu HY, Zhou XJ. Metaplastic thymoma of the mediastinum. A clinicopathologic, immunohistochemical, and genetic analysis. Am J Clin Pathol. 2012;137:261-9.

27. Zhang T, Chen XU, Chu X, Shen YI, Jiao W, Wei Y, et al. Slug overexpression is associated with poor prognosis in thymoma patients. Oncol Lett. 2016;11:306-10.

28. Scheijen B, Bronk M, van der Meer T, De Jong D, Bernards R. High incidence of thymic epithelial tumors in E2F2 transgenic mice. J Biol Chem. 2004;279:10476-83.

29. Hanahan D, Weinberg RA. Hallmarks of cancer: the next generation. Cell. 2011;144:646-74.

30. Liu M, Quek LE, Sultani G, Turner N. Epithelial-mesenchymal transition induction is associated with augmented glucose uptake and lactate production in pancreatic ductal adenocarcinoma. Cancer Metab. 2016;4:19.

31. Rieker RJ, Joos S, Mechtersheimer G, Blaeker H, Schnabel PA, Morresi-Hauf A, et al. COX-2 upregulation in thymomas and thymic carcinomas. Int J Cancer. 2006;119:2063-70.

32. Kang YJ, Mbonye UR, DeLong CJ, Wada M, Smith WL. Regulation of intracellular cyclooxygenase levels by gene transcription and protein degradation. Prog Lipid Res. 2007;46:108-25.

33. Bu Y, Gao L, Gelman IH. Role for transcription factor TFII-I in the suppression of SSeCKS/Gravin/Akap12 transcription by Src. Int J Cancer. 2011;128:1836-42.
34. Koki AT, Khan NK, Woerner BM, Seibert K, Harmon JL, Dannenberg AJ, et al. Characterization of cyclooxygenase-2 (COX-2) during tumorigenesis in human epithelial cancers: evidence for potential clinical utility of COX-2 inhibitors in epithelial cancers. Prostaglandins Leukot Ess Fat Acids. 2002;66:13-18.

35. Majumder M, Landman E, Liu L, Hess D, Lala PK. COX-2 elevates oncogenic miR-526b in breast cancer by EP4 activation. Mol Cancer Res. 2015;13:1022-33.

36. Jiang L, Xiao L, Sugiura H, Huang X, Ali A, Kuro-o $\mathrm{M}$, et al. Metabolic reprogramming during TGFbeta1induced epithelial-to-mesenchymal transition. Oncogene. 2015;34:3908-16.

37. Halazonetis TD, Gorgoulis VG, Bartek J. An oncogene-induced DNA damage model for cancer development. Science. 2008;319:1352-5.

38. Gartel AL, Tyner AL. The role of the cyclin-dependent kinase inhibitor p21 in apoptosis. Mol Cancer Ther. 2002;1:639-49.

39. Cazzalini O, Scovassi AI, Savio M, Stivala LA, Prosperi E. Multiple roles of the cell cycle inhibitor p21(CDKN1A) in the DNA damage response. Mutat Res. 2010;704:12-20.

40. Hernandez-Monge J, Rousset-Roman AB, Medina-Medina I, Olivares-Illana V. Dual function of MDM2 and MDMX toward the tumor suppressors p53 and RB. Genes Cancer. 2016;7:278-87.

41. Feng Y, Lei Y, Wu X, Huang Y, Rao H, Zhang Y, et al. GTF2I mutation frequently occurs in more indolent thymic epithelial tumors and predicts better prognosis. Lung Cancer. 2017;110:48-52.

42. Grajkowska W, Matyja E, Kunicki J, Szymanska S, Marx A, Weis $\mathrm{CA}$, et al. $\mathrm{AB}$ thymoma with atypical type A component with delayed multiple lung and brain metastases. J Thorac Dis. 2017;9: E808-E814.

43. Chang MT, Bhattarai TS, Schram AM, Bielski CM, Donoghue MTA, Jonsson P, et al. Accelerating discovery of functional mutant alleles in cancer. Cancer Discov. 2018;8:174-83. 